Article

\title{
Fuzzy-Based Statistical Feature Extraction for Detecting Broken Rotor Bars in Line-Fed and Inverter-Fed Induction Motors
}

\author{
Cleber Gustavo Dias ${ }^{1, *(\mathbb{D})}$, Luiz Carlos da Silva ${ }^{1}$ (D) and Ivan Eduardo Chabu ${ }^{2}$ (D) \\ 1 Informatics and Knowledge Management Graduate Program (PPGI), Nove de Julho University-UNINOVE, \\ Rua Vergueiro, Liberdade 235/249, Sao Paulo 01504-001, Brazil; luiz.carlos.silva@uni9.pro.br \\ 2 Department of Electrical Automation and Energy Engineering, São Paulo University, São Paulo 05508-070, \\ Brazil; ichabu@pea.usp.br \\ * Correspondence: diascg@uni9.pro.br; Tel.: +55-11-3385-9035
}

Received: 20 May 2019; Accepted: 10 June 2019; Published: 20 June 2019

check for updates

\begin{abstract}
This paper presents the use of a fuzzy-based statistical feature extraction from the air gap disturbances for diagnosing broken rotor bars in large induction motors fed by line or an inverter. The method is based on the analysis of the magnetic flux density variation in a Hall Effect Sensor, installed between two stator slots of the motor. The proposed method combines a fuzzy inference system and a support vector machine technique for time-domain assessment of the magnetic flux density, in order to detect a single fault or multiple broken bars in the rotor. In this approach, it is possible to detect not only the existence of failures, but also its severity. Moreover, it is not necessary to estimate the slip of the motor, usually required by other methods and the damaged rotor detection was also evaluated for oscillating load conditions. Thus, the present approach can overcome some drawbacks of the traditional MCSA method, particularly in operational cases where false positive and false negative indications are more frequently. The efficiency of this approach has been proven using some computational simulation results and experimental tests to detect fully broken rotor bars in a $7.5 \mathrm{~kW}$ squirrel cage induction machine fed by line and an inverter.
\end{abstract}

Keywords: broken rotor bars; induction motor; fuzzy logic; support vector machine; hall sensor

\section{Introduction}

The three-phase induction motors (IMs) are the main electrical rotating machine installed in many industrial environments. Usually, the induction motors are capable of driving various types of load, thus this kind of machine is widely used around the world [1-4]. Although IMs have important advantages, such as robustness, simplicity and lower cost, when compared to other rotating machines (synchronous machines and DC motors, for example) [5], they are subjected to some mechanical and electrical faults, particularly in stator windings, bearings and rotor cage $[1,6]$.

Many researchers and engineers have investigated broken rotor bars and bearing failures in other applications, including commercial cases and industrial plants. Typically, broken rotor bars and cracked end-ring faults share for $5-10 \%$ of induction machine failures, but, as cited in [7], these events are a key issue. As described by [8], for medium-voltage (MV) motors the rotor cage fault is even more common than that of small machines due to the extensive thermal stresses on the rotor. A partial or a fully broken bar increases the machine vibration [9], the current in the rotor bars adjacent to the faulty one and the temperature rise in the motor [7].

The rotor cage fault can also lead to bearing failures and air gap eccentricity [8]. Other researchers, for example, have been discussed the fault in the rotor related to adjacent and nonadjacent broken bars $[10,11]$. Some cases with nonadjacent broken bars are also observed for frequently started motor 
applications. In [12], nonadjacent broken bars for $6.6 \mathrm{kV}, 500 \mathrm{~kW}$, ten-pole induction motor has been reported and although the fault frequency component increases with the number of broken bars, this component is quite difficult to observe if the damaged bars are $90^{\circ}$ (electrical) apart since the asymmetry in the rotor is canceled out $[10,11,13]$.

Particularly for medium voltage (MV) induction motors, the costs related to machine shutdown are much more significant when compared to small motor applications. In [12], an example of a 6.6-kV $2400 \mathrm{~kW}$ eight-pole induction motor was described for rotor under inspection due to a false positive (FP) indication. In this case, an unexpected failure of the motor would result in an estimated financial loss of US 2.5 to US 4.0 million (loss of revenue and repair cost) and a period of 8 to 12 weeks to recover normal plant operation. In other MV applications (Offshore Oil Production Platform), a $11 \mathrm{kV}$ $1950 \mathrm{~kW}$ squirrel cage induction motor inspection has been related for broken rotor bars evaluation and a motor shutdown could take three months of downtime from start to finish and a total financial loss of approximately US 2 million [13]. As cited in [4], for larger motors, longer downtime per failure is related to induction motors starting more than once per day or in cases wherein applications of pulsating load or direct online startups. As aforementioned, in MV motors, the rotor cage fault is even more common than that of small machines due to the extensive thermal stresses on the rotor. In addition, large motors, with hundreds or thousands of kilowats, usually have more rotor bars when compared to small motors; thus, as described by [8], a severe failure is necessary in those rotor cages for successfully applying the traditional motor current signature analysis (MCSA) technique, for rotor conditioning evaluation.

The MCSA has been used in the past two decades to detect broken rotor bars, particularly due to its noninvasive approach [14], by applying fast Fourier Transform (FFT) in only one current phase of the motor $[15,16]$.

The aforementioned MCSA technique is a comprehensive approach for broken rotor bars detection and recognized by researchers and electrical engineers as an efficient diagnosis tool, since this solution is capable of identifying failures in the rotor cage in many cases and applications using only one phase current.

However, MCSA has some limitations and drawbacks well known in literature such as the spectral leakage detected when the motor is working at very low slip, for example, since the amplitude of frequency components, i.e., the left sideband component responsible for an index fault is close to the line frequency [17-20]. It should be mentioned that, in a closed-loop control structure, for example, the harmonics cannot be directly applied, as cited by [21].

The work published by [17] proposed the use of a Hilbert Transform and FFT to extract a fault frequency index for motor running at low slip. However, this approach also requires a long measurement time for current signal processing. It should be noted that MCSA requires an acquisition time of $100 \mathrm{~s}$ for current signal processing to extract the sidebands for failure evaluation. For both cases, it is not possible to detect the fault in transient condition, but only in steady-state, since the slip may change in $100 \mathrm{~s}$.

It is important to highlight that large motors usually operate at low slip even at rated load. In [18], an improvement of the Hilbert method via estimation of signal parameters with rotational invariance technique (ESPRIT) has been proposed to detect broken bars in induction motors running at low slip. In this case, a measurement time equal to $10 \mathrm{~s}$ was used for current signal processing and the motor was line-fed.

Recently, some typical root causes of false positive and false negative indications have been reported using MCSA based rotor fault detection in MV induction motors [12]. The false negative conditions are related to nonadjacent broken bars, load variation and an incorrect speed estimation. The MCSA technique requires an accurate value of the rotor speed (slip) for reliable detection of rotor faults. The work published by [12] still disclosed that, for MV motors, it is necessary an acquisition time of at least 30-60 s for a correct broken bar diagnosis using MCSA. 
In [22], for example, it was described that, in many applications, the rotational speed and the demanded torque of the machines change significantly over time; thus, it is very difficult or almost impossible to have a long enough steady period of time, such as required by MCSA to detect broken rotor bars. The work proposed by [23] requires the slip information to extract some fault frequencies from vibration and sound of the machine, but the authors highlighted that, in field applications, motor speed is not always available. The typical root causes of false positive (FP) and false negative (FN) indications produced by MCSA-based rotor fault detection are: load variation (FN), incorrect speed estimation (FN) and low frequency load oscillations (FP), as cited by [12,24,25]. As mentioned by [8], load oscillation can also induce current harmonics at the same frequencies in the stator current, such as those found in damaged cage rotors.

Recently, some researchers have also investigated the broken rotor bars in induction motors fed by an inverter. As cited by [26-28], the rotor fault detection in converter-fed induction motors has some drawbacks when compared to a sinusoidal supply situation, particularly due to the additional harmonics that will be induced in the current spectrum. Other works have also reported difficulties in detecting rotor faults for the motor fed by an inverter, such as in [22,29-31]. In [32], a method for broken rotor bars detection relies on monitoring certain statistical parameters estimated from the analysis of the start-up stator current envelope. In this case, the simulations results were carried out for motor running under direct online start and inverter-fed modes, but this research did not address cases of load variation and/or load oscillation.

In [5], the analysis of the startup current (ATCSA) of the motor was also proposed to detect broken rotor bars. This approach applies time-frequency (T-F) transforms for the continuous analyses, i.e., a Short Time Fourier Transform (STFT) and a Discrete Wavelet Tranform (DWT) for the computation of a fault severity indicator in line-fed motors. This paper shows an interesting application of the ATCSA method in four induction motors operating in mining facilities, but this technique requires an specialist interpretation of a V-shaped image responsible for failure evaluation and the presence of several breakages in the rotor cage for a relevant fault severity indicator (DWT should lead to a value lower than the threshold level $50 \mathrm{~dB}$ ). This work did not address the use inverter-fed mode. The authors disclosed that the method is able to detect the rotor failure with accuracy severity levels around one broken bar out of 28 , but large induction motors usually have more than four or five tens of bars. Table 1 shows the specifications for some induction motors with lots of rotor bars.

Table 1. Specifications for some induction motors with lots of rotor bars.

\begin{tabular}{lccccc}
\hline Rated Power kW (hp) & Rated Voltage & Rotor Bars & Rated Slip & Application & Reference \\
\hline $127 / 70(170 / 94)$ & $415 \mathrm{~V}$ & 88 & $1.33 \%$ & Heavy duty cycle mixed motor & [33] \\
$134(180)$ & $440 \mathrm{~V}$ & 58 & $1 \%$ & Motor-gearbox-compressor & [34] \\
$1656(2220)$ & $2.3 \mathrm{kV}$ & 76 & $0.8 \%$ & High pressure pump & [25] \\
$1950(2614)$ & $11 \mathrm{kV}$ & 60 & $1 \%$ & Large LP Compressor & [34] \\
$2800(1200)$ & $6 \mathrm{kV}$ & 117 & - & - & {$[35]$} \\
$2984(3750)$ & $6 \mathrm{kV}$ & 155 & $0.44 \%$ & & [35] \\
$3600(4285)$ & $6.6 \mathrm{kV}$ & 46 & $0.55 \%$ & Large sea water injection pump \\
\hline
\end{tabular}

It is important to mention that the work published by [36] has shown a survey of existing broken rotor bar fault detection techniques based on fault signatures analysis and the authors pointed out that time-frequency representation using Wavelet Transform is a powerful tool, but it suffers from some drawbacks, as the need for optimum selection of the mother wavelet and the overlap between adjacent frequency bands. The same work also described that other researchers are investigating the limitations of the detection based on MCSA, especially the load variation, since it produces frequency components in the current spectrum close to the broken bar fault indicator.

In addition to the processing methods, other works also employed different approaches to identify faults in rotational electrical machines, such as computational intelligence algorithms and/or machine learning techniques. In [37], for example, novel insights have been discussed for the classifier 
evaluation in the field of electric machine diagnosis using Decision Tree (DT) and support vector machine (SVM). In this case, the authors pointed out that the choice of a correct classifier depends enormously on the accurate evaluation of its performance, in order to reduce the occurence of false diagnosis in predictive maintenance. A case study was presented in [37] and a rotor condition of a small induction motor $(0.75 \mathrm{~kW})$ has been tested using the MCSA method. However, this approach did not consider the load variation for validation purposes.

In [30], four different learning machine techniques were investigated for broken rotor bars detection in a three-phase induction motor fed by an inverter. In this case, a fuzzy ARTMAP network, SVM, a k-nearest neighbour (KNN) and a multilayer perpetron network (MLP) have been tested for broken bars evaluation using the motor current as a source signal for an acquistion time duration of $6 \mathrm{~s}$. This work has shown the potential of the machine learning approaches for failure detection at different speeds, but the load variation and load oscillation did not address.

In [38], a neuro-fuzzy approach was applied to locate broken rotor bars in induction motors running at very low slip. In this work, a Fast Fourier Transform was used to extract the features from a Hall effect sensor installed inside the machine and it was used an acquisition time duration of $4 \mathrm{~s}$. The processed signal was the magnetic flux density measured by the Hall sensor. This research also did not address the rotor fault detection in variation or oscillating loads, only in steady-state condition.

In [39], three learning machine techniques (MLP, KNN and SVM) were used to detect and classify rotor faults also running at low slip. In this case, some frequency and statistical features have been used to evaluate the rotor condition in an acquistion time of $4 \mathrm{~s}$ for motor running at steady-state. In [40], an investigation of vibration and current monitoring for effective fault prediction in an induction motor has been proposed using a multiclass support vector machine algorithm and in [41], and a lot of signal processing and feature extraction techniques were described for fault diagnosis in rotating machines, such as time-domain and frequency domain approaches, as well as the use of KNN, SVM and Fuzzy c-Means classifiers, among others.

Although the works published by [39-42] have successfully used machine learning methods for electrical and/or mechanical failures diagnosis, they did not address the problem related to load variation or load oscillation for broken rotor bars detection.

As can be seen, today, a wide time-domain and frequency-domain signal processing techniques are used for feature extraction and the rotor condition monitoring systems are also strongly related to the use of computational intelligence techniques or machine learning approaches, due to a huge amount of data acquired by sensors.

This paper presents the use of a fuzzy inference system (FIS) to extract the features of a Hall sensor signal, installed inside the motor, according to the rotor condition. The FIS is able to quantify crisp values from a physical environment, i.e., by using the uncertainty representation of the magnetic flux disturbances. As described by [43], the vast majority of the related studies is focused on noninvasive techniques, such as the measurement of stator current and vibration, among others. These approaches are understandable from a cost perspective, since an external sensor is easy to install; thus, it means that a small extra cost is necessary compared to the cost of a standard induction motor. However, [43] states that there are special motors designed for particular applications and these machines are usually expensive and not easy to replace. In this case, large induction motors (tens or hundreds of kilowatts) often operate in extreme dynamic environments under increased stresses. Therefore, a new apparatus that helps preventing an unexpected downtime is an acceptable, or interesting, option.

The analysis of broken bars is taken into account for time-domain purposes, including the signal processing of the signal and the data classification using an SVM classifier. The reason for using this machine learning classifier is justified with earlier studies of multi-class classifiers [40,41].

Based on the aforementioned literature, this paper proposes a method to detect fully broken rotor bars in large IMs, since this kind of motor usually has lots of rotor bars and also reduces the false positive and false negative indications for rotor cage condition evaluation. For these purposes, the present approach is focused on the following contributions: 
(i) It is not necessary to estimate rotor slip, as required by the MCSA method and other techniques (related to FN indication);

(ii) It is possible to detect broken bars during load variation (related to FN indication);

(iii) It is possible to detect broken bars during low frequency load oscillations (related to FP indication);

(iv) It is possible to classify the severity of rotor faults;

(v) It is possible to detect broken rotor bars for motor running at low slip (related to FN indication); and

(vi) The method allows the rotor fault detection for motor fed by an inverter and also fed by sinusoidal power supply.

The present approach has been validated by using simulation results of two IMs (1200 kW and $7.5 \mathrm{~kW}$ ) and experimental tests have been performed using an induction motor of $7.5 \mathrm{~kW}, 220 \mathrm{~V}$ and 38 rotor bars, fed by a sinusoidal supply and by an inverter. The methodology and the results are presented in the following subsections.

\section{Methodology for Feature Selection and Broken Bars Detection}

In the present approach, the detection of broken bars is taken into account in the time-domain, analysing the signal from a Hall effect sensor and its disturbances. This work includes four main stages: (i) signal acquisition from Hall sensor; (ii) signal processing in the time domain; (iii) feature extraction using fuzzy logic; and (iv) fault classification stage using an SVM classifier. The signal processing stage includes a filter step, a zero-crossing detector and an algorithm for a valley inflection point's detection. A second one includes a fuzzy inference system to extract the features of the Hall sensor signal for each positive and negative half-cycle.

The last stage was used for data classification and was applied not only to detect the rotor failure, but also to classify the fault severity. Each step of this methodology is described in the following sections. Figure 1 shows the methodology for broken bars diagnosis using the proposed method.

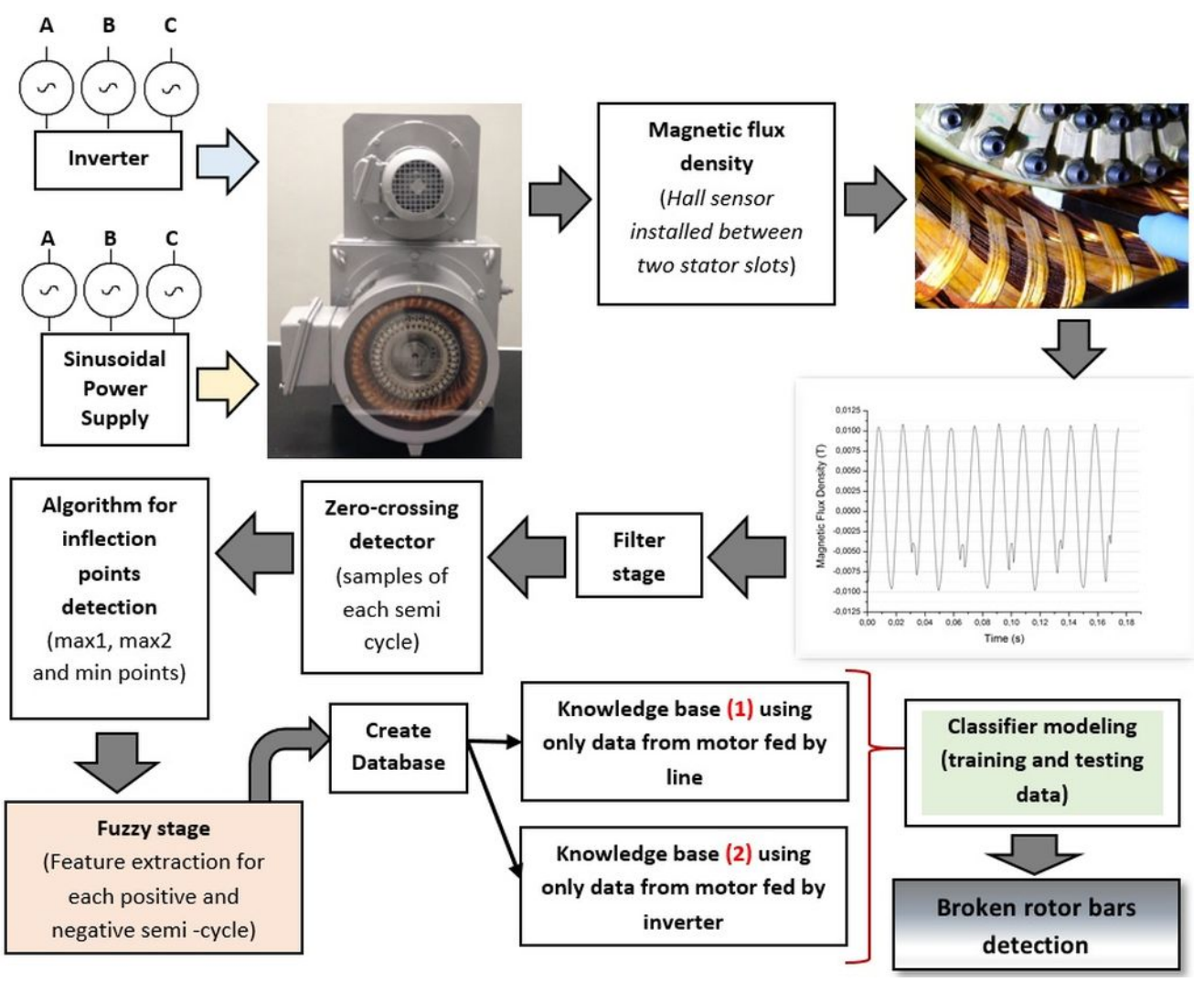

Figure 1. Methodology of evaluation for broken rotor bars diagnosis. 


\subsection{Signal Acquisition Stage}

Air Gap Disturbances Monitoring Using A Hall Effect Sensor

As mentioned before, in this paper, the magnetic air gap disturbances have been used to evaluate the rotor condition. Other works have demonstrated the possibility to detect broken rotor bars using this kind of signal and a Hall sensor installed between two stator slots of the machine $[19,38,39,44]$. In [45], an array of Hall effect sensors was installed around the stator circumference inside the motor air gap to detect rotor bar damage and stator turn-to-turn shorts. In this case, 36 measurements points have been used for fault detection. However, the solution proposed by [45] requires a lots of measurement points and the other Hall sensor based solutions did not take into account the motor fed by an inverter or driven by oscillating loads. In this work, the Hall sensor was installed close to the air gap. This sensor is able to monitor the leakage flux, or the magnetic flux density, created by the overhang portion (rotor bar portion) between the core and the end ring.

In [46], for example, the air gap flux analysis was used to evaluate the broken bars in a $42 \mathrm{~kW}$ induction motor with 58 rotor bars, and it was possible to observe the disturbances in the resultant magnetic flux density according to the failure, as shown in Figure 2. The mathematical model disclosed in [46] shows that, when broken bars are distributed around the rotor, there is a valley created by flux perturbation, as shown in Figure 2. The valley can be observed, especially when broken bars are near the sensor, for both positive half-cycle and negative half-cycle. In this work, this feature has been extracted and quantified by a fuzzy inference system, after the signal processing stage, to create two databases (sinusoidal and inverter supplies) for further rotor evaluation using an SVM classifier.

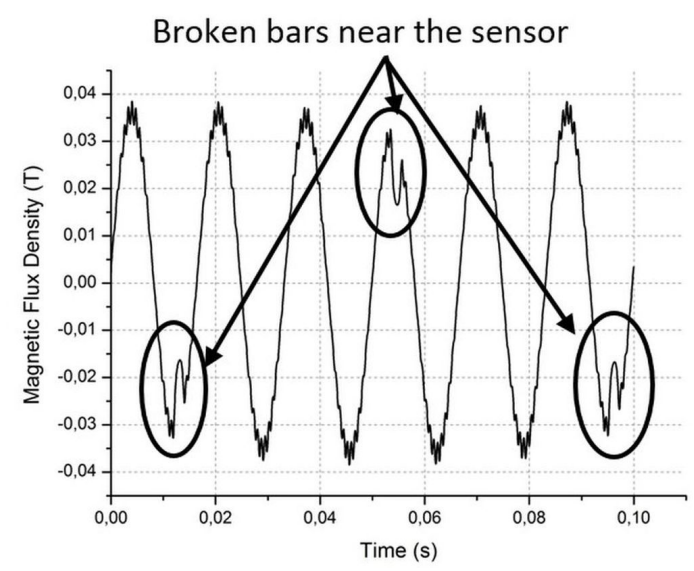

Figure 2. Resulting magnetic flux in the Hall sensor for a damaged rotor (two adjacent broken bars).

\subsection{Signal Processing Stage}

\subsubsection{Filter Step}

In order to reduce the noise in the original signal from the Hall sensor and to contribute to half-cycle detection, a filter stage was applied by using a Butterworth sixth order low pass filter in a cutoff frequency of $800 \mathrm{~Hz}$. Note that the signal from sensor, i.e., the resulting magnetic flux density is in the $60 \mathrm{~Hz}$ frequency.

\subsubsection{Zero-Crossing Detector}

A zero-crossing detector for broken bars signal was used to identify and to separate positive and negative half cycles. In the present work, the signal is stored as input data for inflection point detection, as described in the next section. This stage is able to identify transitions between negative and positive values of the magnetic flux density. 


\subsubsection{Algorithm for Inflection Point Detection in the Valley}

After undergoing a filtering stage and a zero-crossing detector, the Hall Effect sensor signal is treated by an algorithm capable of identifying inflection points in each valley, as shown in Figure 3 . In this case, one sampling counter and an input data vector were considered for inflection point detection. A cutting line was applied in the input data and two reading movements were used for determining three inflections points, such as Max1, Max2 and Min values. The best cutting line position was investigated, since this line is crucial for " $\mathrm{min}$ " point location. It is important to mention that the "min" point position, or the valley, depends on the broken bar position relative to the Hall Effect sensor and to instantaneous rotor currents.

If the cutting line is applied in the middle of this half-cycle, for example, Max1 and Max2 points will be close together and the Min point will be found in a wrong way. After a series of experimental tests, the best cutoff value (cutting line) was defined as being $40 \%$ of the sample set on each half-cycle (left shifted). Essentially, the inflection points were detected not only to estimate broken bars, but also to evaluate the fault severity in the rotor cage. In the next section, the fuzzy inference machine implemented is described in detail.

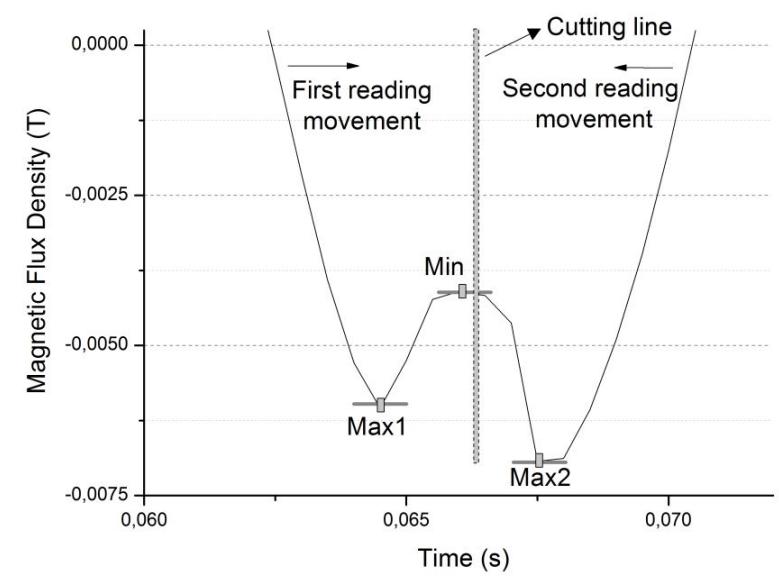

Figure 3. Inflection points used for fuzzy approach in the valley and cutting line used to determine Max1 and Max2 points.

\subsection{Feature Extraction Stage}

\subsubsection{Fuzzy Logic for Valley Quantification and Feature Extraction}

Normally, the operational conditions of an equipment or process are given in terms of numerical values [47-50]. On the other hand, the fuzzy systems incorporated linguistic expressions capable of determining human behavior, or more precisely, the human experiences. Thus, a fuzzy logic technique applies its two major components, such as membership functions and fuzzy rules to quantify each half-cycle of the signal from the Hall Effect sensor. In other words, in case of failure, for example, fuzzy logic translates some numerical values of a valley into some linguistic features as better described in the next subsections.

\subsubsection{Membership Functions}

The reason for using a fuzzy inference machine regards the uncertainty of the failure diagnosis according to the number of broken bars and their position in the rotor. Thus, the fuzzy system is able to quantify the depth and the type of valley, in case of faults, according to the amplitude and the position of an inflection point (Min) from the signal. Therefore, these two input parameters ("Min" value and 
"Min" inflection position) were used for the proposed fuzzy system to estimate its output, such as the type of valley.

In the present approach, the fuzzification process works for each half-cycle. After zero-crossing detector stage, the maximum amplitude, or peak value, for each positive and negative half-cycle is stored in memory. For positive cycles, for example, the algorithm identifies the maximum value between all half-cycles and this value is used as a MAX value, such as shown in Figure 4.

This MAX value works as a threshold for establish the linguistic terms. In this case, the amplitude of "min" point is distributed in seven terms as follows: EL (Extremely low), VL (Very low), L (Low), F (Fair), H (High), VH (Very high) and EH (Extremely high).

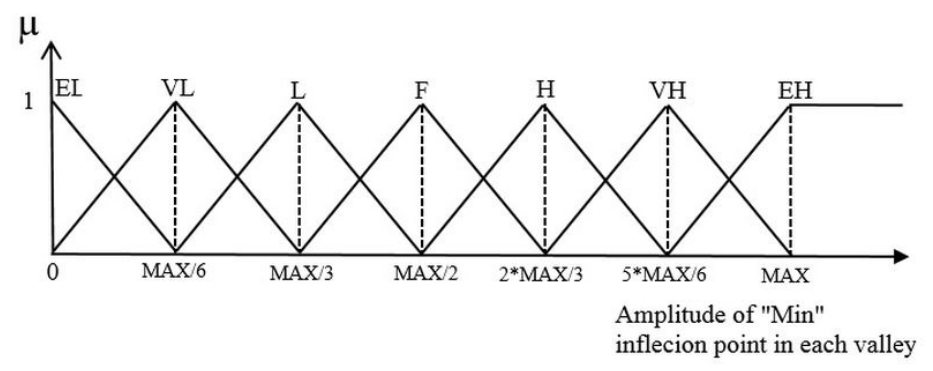

Figure 4. Membership functions for amplitude of "min" point.

Figure 5 shows a typical signal from Hall sensor for a faulted rotor. In this case, there is a sample with six positive half-cycles and three valleys. In this case, the maximum amplitude is near $0.03 \mathrm{~T}$ ("MAX" value related to half-cycle 2), but the "min" points (Min1, Min3 and Min5), calculated after the inflection point detection stage, are smaller than this value. Thus, the fuzzification process uses this MAX value as a reference and the " $\mathrm{min}^{\prime}$ " value is fuzzified according to membership functions presented in Figure 4.

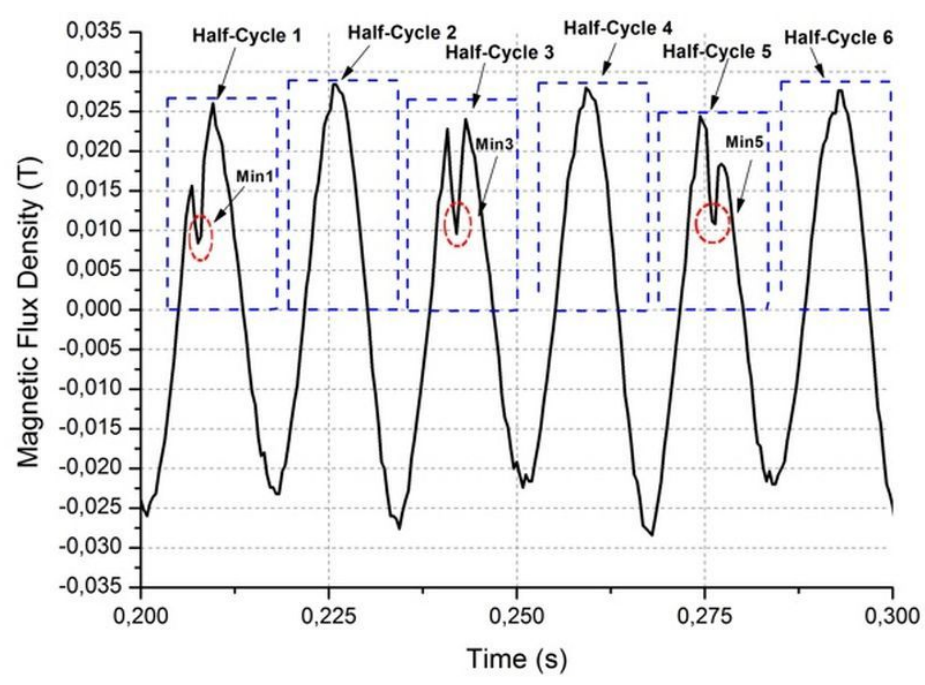

Figure 5. A typical signal from the Hall sensor for a broken rotor bar.

In a similar way, each half-cycle has a number of samples stored in a memory (sample vector)

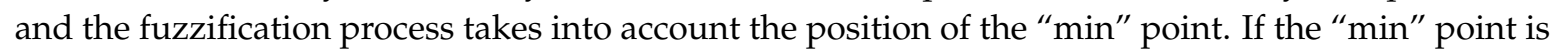
located in the middle of the sample vector (half-cycle 3), for example, the "min" point is fuzziified for a position "C" (Figure 6).

The linguistic terms for "SAMPLE" value are distributed as follows: TL (Top left), VL (Very left), LL (Little left), VLL (Very little left), C (Center), VLR (Very little right), LR (Little right), VR (Very right) and TR (Top right). As can be seen in Figure 6, the number of samples for each half-cycle was divided 
in nine linguistic terms; thus, if the number of samples is around 240, for instance, and the "min" point position for a specific half-cycle is around 120, this inflection point is in the center position.

In other words, if the "min" point is located at the position 30, this point is in the very left position. Figure 7 shows the membership functions for output variable; in this case, the severity of valley. As can be seen, the output has been distributed in ten linguistic terms: $\mathrm{H}$ (Healthy rotor-no valley), NS (Not severe), VLS (Very little severe), LS (Little severe), MS (More severe), F (Fair), SE (Severe enough), VS (Very severe), ES (Extremely severe) and AS (Absolutely severe).

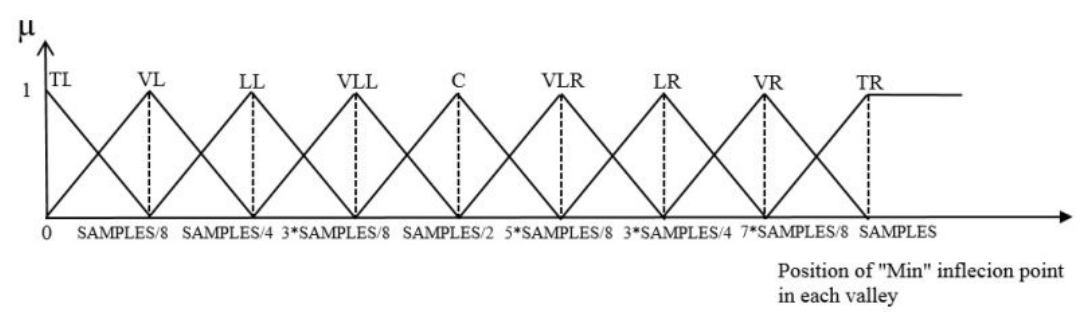

Figure 6. Membership functions for samples of "min" point.

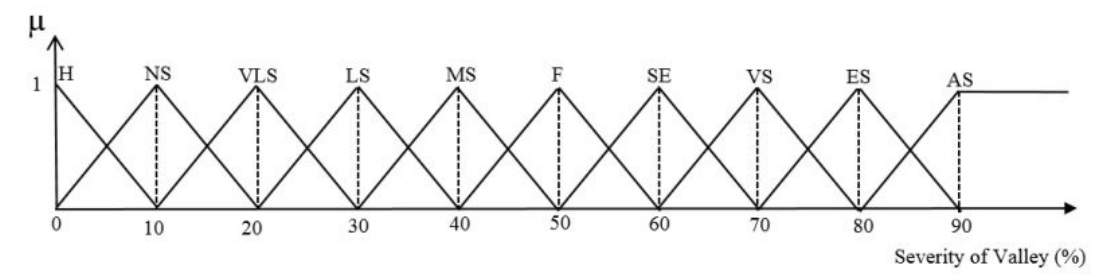

Figure 7. Membership functions for severity of valley.

\subsubsection{Fuzzy Rules}

Then, the fuzzy rules are the main knowledge of the present fault diagnostic system, able to distinguish different severity valleys. Table 2 summarizes some fuzzy rules applied to the present approach. The defuzzification process must be used for translating the rule base into numerical values for each scaled membership function, as presented in Table 2.

Table 2. Some fuzzy rules for valley severity condition.

\begin{tabular}{lcc}
\hline \multicolumn{1}{c}{ If Amplitude Is } & In addition, Position Is & Then, Severity Is \\
\hline Extremely Low (EL) & Very Little Left (VLL) & Extremely Severe (ES) \\
Very High (VH) & Very Little Right (VLR) & Little Severe (LS) \\
Very High (VH) inc & Top Right (TR) & Not Severe (NS) \\
\hline
\end{tabular}

The Center of Maximum (CoM) defuzzification method [47] was applied for determining numerical values for each half-cycle, both for positive and negative samples. Thus, the condition of each half-cycle, i.e., the existence of a valley and its severity for a magnetic flux density collected from a Hall sensor is calculated after the fuzzification inference, and the output is given by Equation (1):

$$
\text { fout }=\frac{\sum_{r=1}^{n}\left(x_{r} \cdot \mu_{r}\right)}{\sum_{r=1}^{n}\left(x_{r}\right)}
$$

where $x_{r}$ is the typical numerical, or crisp value for the scaled membership function $n$, and $\mu_{r}$ is the degree of membership at which membership function $n$ was scaled. Equation (1) refers to a weighted average method for the defuzzification process and $n$ is related to each output membership function. In this work, the output of the fuzzy system suggests the severity of an eventual valley, according to numerical values between zero and $100 \%$. After the fuzzification step, each half-cycle was quantified and some statistical data have been calculated and used as inputs to an SVM classifier to proceed the 
rotor fault diagnosis. In the next section, the statistical features and the SVM structure are discussed in further detail.

\subsubsection{Statistical Data of Each Fuzzified Half-Cycle}

As mentioned by [41,51], there are common statistical features in the time domain to evaluate the mechanical structure of a rotating machinery. In [51], for example, 16 time domain statistical features have been selected with other frequency domain features for rotor fault detection. In that case, the induction motor was fed both for direct line and inverter, but the slip estimation for rotor condition evaluation was necessary.

The work published by [39] disclosed the use of some statistical data to perform the magnetic density evaluation of a signal produced by a Hall sensor installed inside an induction motor. In that case, the following features have been used: mean, root mean square, variance, kurtosis and skewness. In [39], the broken bars detection was performed for a motor fed by sinusoidal voltage and some frequency domain data have been also considered. Based on these previous works, in this study, the mean, standard deviation, root mean square, variance, kurtosis and skewness were calculated for each fuzzified half-cycle, as described in Equations 2, 3, 4, 5 and 6:

- Mean

$$
\mu^{i}=\frac{1}{N} \sum_{j=1}^{n}\left[\left(x_{j}^{i}-\mu^{i}\right)\right]
$$

- $\quad$ Root mean square (RMS)

$$
R M S=\sqrt{\frac{1}{N} \sum_{j=1}^{n}\left[\left(x_{j}^{i}-\mu^{i}\right)^{2}\right]},
$$

- Variance

$$
\sigma^{2}=\frac{1}{N-1} \sum_{j=1}^{n}\left[\left(x_{j}^{i}-\mu^{i}\right)^{2}\right]
$$

- Kurtosis

$$
\operatorname{KUR}=\frac{1}{(N-1) \sigma^{4}} \sum_{j=1}^{n}\left[\left(x_{j}^{i}-\mu^{i}\right)^{4}\right]
$$

- Skewness

$$
S K W=\frac{1}{(N-1) \sigma^{3}} \sum_{j=1}^{n}\left[\left(x_{j}^{i}-\mu^{i}\right)^{3}\right] .
$$

Moreover, the deepest fuzzy valley (DFV) and the number of valleys with output greater than "More Severe" (NVS) of each sampled window were considered as additional features for SVM classifier. It is important to highlight that all features have been extracted using the fuzzy inference model; thus, the statistical values were calculated from the fuzzified magnetic flux density disturbances. Therefore, the input vector (eight fuzzy features) for the classifier was defined as:

$$
X(\text { input })=\left[\text { Mean }, R M S, \sigma^{2}, \sigma, K U R, S K W, D F V, N V S\right] .
$$

\subsection{Fault Classification Stage}

\section{Support Vector Machine Based Fault Diagnosis}

As mentioned by [41], the support vector machine learning technique is based on statistical learning theory and is widely used for classification problems in various fields. The work published by [41] also described that SVM has a simple structure, an excellent generalization performance and a fast learning speed. In addition, the SVM was chosen due its interesting performance for a multiclass 
problem of this research (severity of the rotor fault). As cited by [39,52], an SVM classifier uses an optimization problem to find the best hyperplane that separates target classes.

The kernel function of the SVM is crucial for its performance, as cited by [39,41], and the cost tuning parameter $(\mathrm{C})$ is also very important for the classification performance. Therefore, in this work, the cost value was chosen in a range of $(0,200)$ [39]. In addition, three of the most used kernel functions were selected for broken bars detection, such as quadratic, Gaussian and linear. Since the present approach takes into account a multiclass problem, the classification strategy of SVM was the One-against-One (OAO), as disclosed and used by [40]. Therefore, in this work, the SVM has eight inputs, as defined by Equation (7) and only one output capable of classifying 5 classes for an induction motor fed by direct-line (healthy, one broken bar (1BB), two broken bars (2BB), three broken bars (3BB) and four broken bars (4BB) and three classes for a motor fed by an inverter (healthy, one broken bar (1BB) and three broken bars (3BB)). The training time of each SVM topology was less than $6 \mathrm{~s}$ using the Matlab toolbox (Matlab2016b, Mathworks). The best SVM model, for example, was trained in less than $2 \mathrm{~s}$ and the elapsed time was around $0.084 \mathrm{~s}$ to validate the sinusoidal cases and around $0.052 \mathrm{~s}$ to validate the inverter-fed cases.

\section{Computational Simulation Results}

This section shows the computational simulation results for two induction motors, as shown in Table 3, using the present approach. For each motor, the simulation took into account a mathematical model developed in [46], i.e., the magnetic flux density in the Hall Effect sensor to evaluate broken bars in the rotor cage. This model was also applied in [44] to evaluate the broken rotor bars in frequency domain, but in steady-state. In this case, the model was simulated in the MATLAB/Simulink software.

Table 3. Rotor of some motors used for computational simulation.

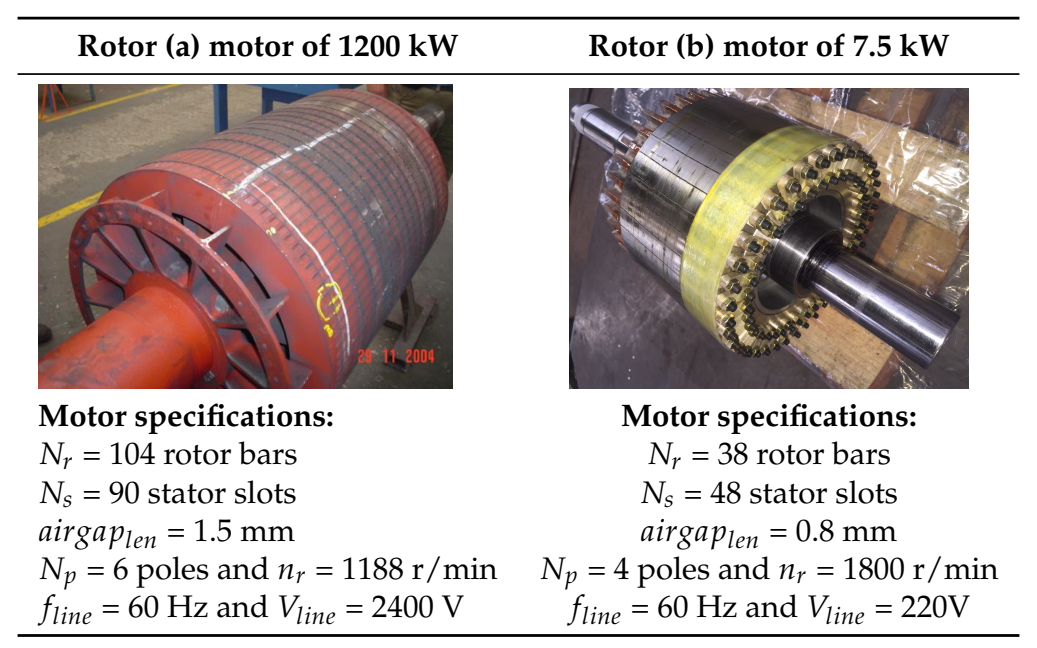

\subsection{Mathematical Model for Simulation Broken Rotor Bars}

As mentioned before, the computation simulation for broken rotor bars detection has been performed using the mathematical model developed in [46]. In this model, a comparison between simulation and experimental results has been made for a $42 \mathrm{~kW}$ induction motor, for different load torque conditions (distinct slip values), for which it has demonstrated a good approximation between these approaches. In Figure 8, for example, it is possible to observe the simulated and experimental results obtained for a resulting magnetic flux density due to broken rotor bars in a $42 \mathrm{~kW}$ induction motor. 


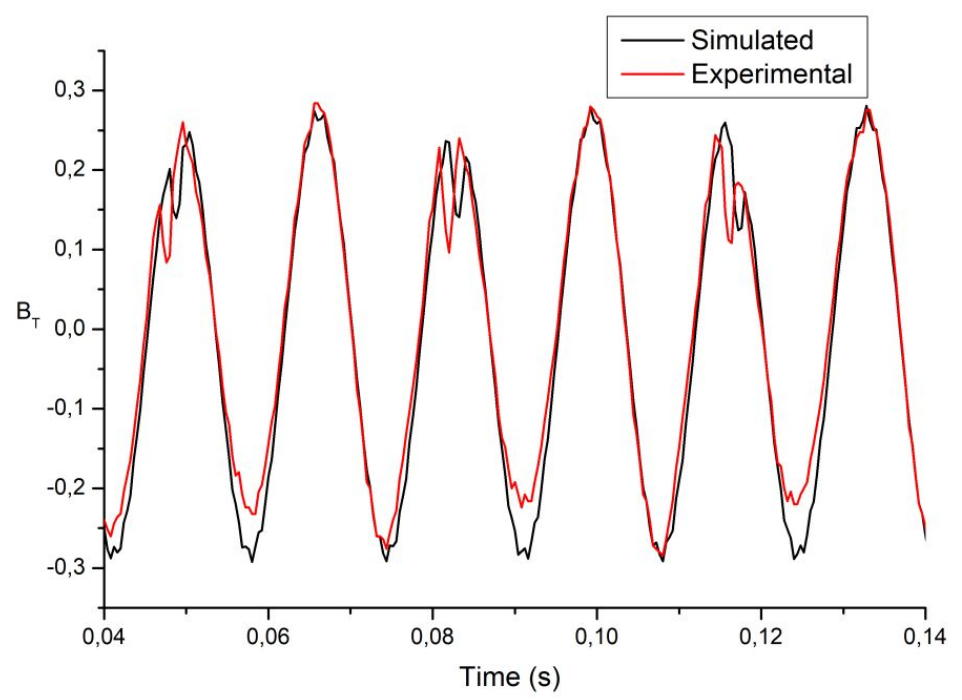

Figure 8. Resulting magnetic flux density for broken rotor bars (simulated and experimental values).

In that approach, the resulting magnetic flux density variation in the Hall effect sensor can be defined by applying Biot Savart in a conductor. For an induction motor, each conductor is a rotor bar from a squirrel cage. Equation (8) describes the resultant magnetic contribution produced by each rotor current $\left(B R_{r}\right)$, using Biot Savart concept, as better described in [44,46]:

$$
B R_{r}=\frac{\mu_{0}}{2 \pi} \sum_{n=1}^{N_{r}}\left[\frac{\operatorname{Im}}{\operatorname{Dist}}\left(\sqrt{\left.1-\left[\frac{(R-w) \sin (B+(n-1) \cdot \lambda)}{d_{n}}\right]\right)}\right]^{2} \cdot \cos \left(\alpha_{n}\right),\right.
$$

where:

$N_{r}=$ number of rotor bars;

$R$ = Radius of rotor structure;

$\lambda=$ angular distance between two rotor bars.

The variable $I m$ is related to the maximum current on each rotor bar; thus, it is possible to simulate a damaged bar setting its value to zero. When a broken rotor bar is near the Hall Effect sensor and its current would be maximum positive or negative value, there is a valley in the peak of the resulting magnetic flux. It should be noted that this signal is a $60 \mathrm{~Hz}$ frequency, for any machine pole pairs.

For calculation of the total magnetic flux density, Biot Savart was also applied to stator currents $\left(B_{s} d\right)$, considering a double layer for stator coils. Therefore, the mathematical model for simulation purposes is given by:

$$
B_{T}=B R_{r}+B_{s} d
$$

\subsection{Case 1: Induction Motor of $1200 \mathrm{~kW}, 6$ Poles and $2.4 \mathrm{kV}$}

In this subsection, the simulation results of an induction motor of $1200 \mathrm{~kW}, 90$ stator slots, 104 rotor bars, three pole pairs, $1188 \mathrm{r} / \mathrm{min}$ and $60 \mathrm{~Hz}$ are shown and discussed. The rated load torque is 9650 N.m. This motor was coupled to an industrial fan and its rotor was affected by broken rotor bars. The Runge-Kutta (fourth order) numerical simulation was used in Matlab/Simulink environment and a sample frequency of $10 \mathrm{kHz}$ was applied for Hall sensor data. Figure 9a shows the peak signal distortion for each rotor condition and Figure $9 \mathrm{~b}$ shows the valley severity after the fuzzification process, in a rated load torque (slip $=1 \%$ ). 


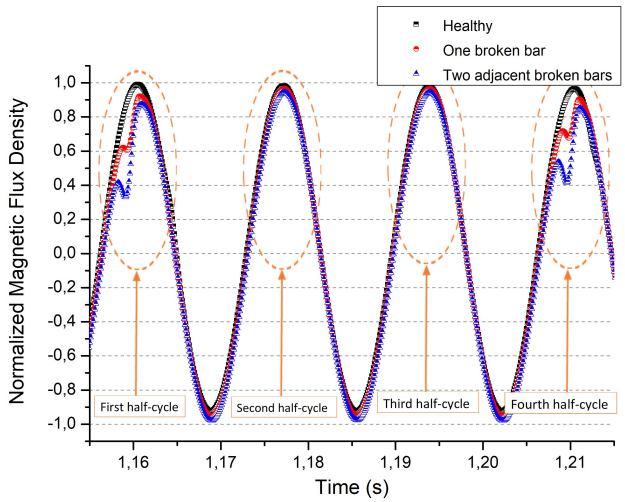

(a)

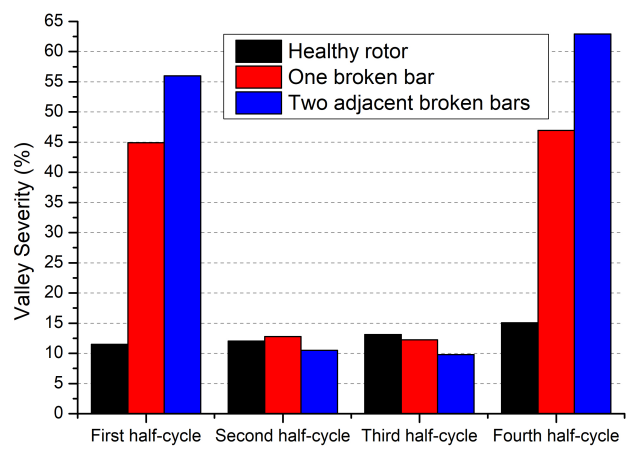

(b)

Figure 9. Simulation of the magnetic flux density in a rated load torque (stead steady regime at slip = $1 \%$ ) for $1200 \mathrm{~kW}$ induction motor showing: (a) flux disturbances near the air gap (peak signal distortion (valley) for each rotor condition (positive half-cycles)) and (b) cycles after fuzzification stage (fuzzified valley severity for each rotor condition ).

Table 4 shows the fuzzified statistical values found in different simulation cases. For a healthy condition, for example, it is possible to observe the smaller values for SKW, $\sigma^{2}, \sigma$ and DFV parameters, even for oscillating loads, when compared to damaged rotors. These input data were applied to the SVM classifier to rotor condition evaluation, as described in Section 4.

Table 4. Some typical statistical data according to rotor conditions for $1200 \mathrm{~kW}$ induction motor simulation.

\begin{tabular}{|c|c|c|c|c|c|c|}
\hline Scenario & KUR & MEAN & SKW & $\sigma^{2}$ & $\sigma$ & DFV \\
\hline Healthy (steady state at slip $=0.91 \%$ ) & 9.88 & 11.78 & -1.41 & 7.95 & 2.66 & 17.09 \\
\hline Healthy (oscillating load slip in $0.87 \%$ to $0.93 \%$ ) & 2.37 & 14.7 & 0.42 & 12.58 & 3.28 & 21.92 \\
\hline Healthy (oscillating load in the slip range of $0.84 \%$ to $0.97 \%$ ) & 2.46 & 12.84 & 0.89 & 6.82 & 2.72 & 19.39 \\
\hline $1 \mathrm{BB}$ (steady state at slip $=0.91 \%$ ) & 11.53 & 13.19 & 1.91 & 47.25 & 6.29 & 38.09 \\
\hline $1 \mathrm{BB}$ (load variation in two slips $(0.44 \%$ and $0.91 \%))$ & 9.96 & 18.15 & 1.81 & 38.9 & 5.51 & 37.58 \\
\hline $1 \mathrm{BB}$ ((oscillating load in the slip range of $0.88 \%$ to $0.91 \%))$ & 9.59 & 15.07 & 2.98 & 87.16 & 9.18 & 49.27 \\
\hline $1 \mathrm{BB}(($ oscillating load in the slip range of $0.87 \%$ to $0.93 \%))$ & 19.75 & 14.36 & 4.18 & 44.64 & 6.62 & 48.29 \\
\hline $1 \mathrm{BB}$ ((oscillating load in the slip range of $0.84 \%$ to $0.97 \%))$ & 13.91 & 14.68 & 2.93 & 43.23 & 6.34 & 44.64 \\
\hline 2BB (steady state at slip $=0.91 \%)$ & 9.84 & 14.11 & 1.80 & 102.12 & 8.93 & 49.65 \\
\hline
\end{tabular}

\subsection{Case 2: Induction Motor of $7.5 \mathrm{~kW}, 4$ Poles and $220 \mathrm{~V}$}

In this subsection, the simulation results of an induction motor of $7.5 \mathrm{~kW}, 48$ stator slots, 38 rotor bars, two pole pairs, $1740 \mathrm{r} / \mathrm{min}$ and $60 \mathrm{~Hz}$ are shown and discussed. The rated load torque is 40 N.m. In this case, the Runge-Kutta (fourth order) was also used in a Matlab/Simulink environment and a sample frequency of $10 \mathrm{kHz}$ was applied for Hall sensor data. Figure 10a shows the peak signal distortion for each rotor condition and Figure $10 \mathrm{~b}$ shows the valley severity after the fuzzification process, in $1 / 4$ load torque (slip $=0.92 \%$ ). The rated slip is $3.33 \%$.

Table 5 shows the fuzzified statistical values found in different simulation cases. As the previous case, for a healthy condition, there are smaller values for SKW, $\sigma^{2}, \sigma$ and DFV parameters, even for oscillating loads, when compared to a faulted rotor. These input data were also applied to the SVM classifier to rotor condition evaluation, as described in Section 4. 


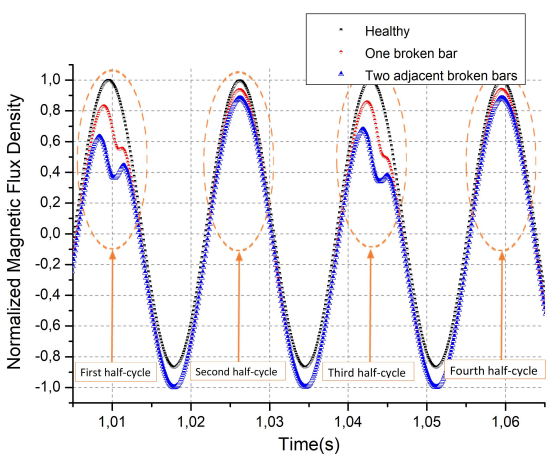

(a)

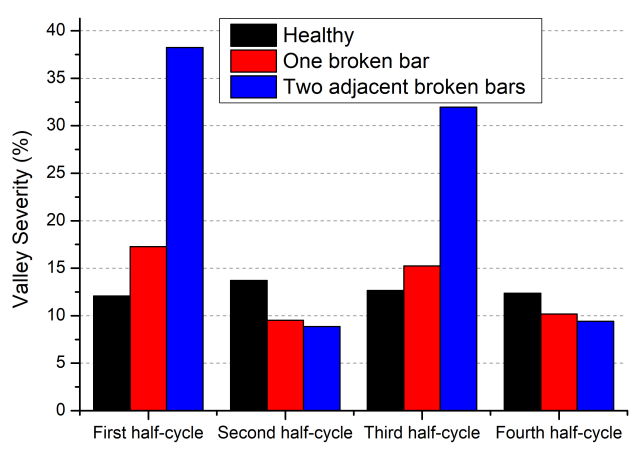

(b)

Figure 10. Simulation of the magnetic flux density in stead steady regime at $1 / 4$ load torque (slip $=0.92 \%$ )) for $7.5 \mathrm{~kW}$ induction motor showing: (a) flux disturbances near the air gap (peak signal distortion (valley) for each rotor condition (positive half-cycles)) and (b) cycles after fuzzification stage (fuzzified valley severity for each rotor condition ).

Table 5. Comparison between some typical statistical data according to rotor conditions for $7.5 \mathrm{~kW}$ induction motor simulation.

\begin{tabular}{lcccccc}
\hline \multicolumn{1}{c}{ Condition } & KUR & MEAN & SKW & $\sigma^{\mathbf{2}}$ & $\sigma$ & DFV \\
\hline Healthy (steady state at slip = 0.92\%) & $\mathbf{8 . 9 3}$ & $\mathbf{1 2 . 2 7}$ & $-\mathbf{1 . 3 1}$ & $\mathbf{1 6 . 0 2}$ & $\mathbf{3 . 2 6}$ & $\mathbf{1 7 . 9 3}$ \\
Healthy (oscillating load in the slip range of $\mathbf{2 . 6 \%}$ to $\mathbf{2 . 8 \%})$ & $\mathbf{6 . 3 6}$ & $\mathbf{1 3 . 5 7}$ & $\mathbf{- 1 . 4 4}$ & $\mathbf{1 6 . 8 4}$ & $\mathbf{3 . 5 1}$ & $\mathbf{1 9 . 3 5}$ \\
1BB (steady state at slip = 0.92\%) & 4.79 & 14.86 & 1.38 & 76.73 & 7.83 & 40.12 \\
1BB ((oscillating load in the slip range of 2.6\% to 2.8\% )) & 4.74 & 18.26 & 1.95 & 112.76 & 10.52 & 54.7 \\
2BB (steady state at slip = 0.92\%) & 3.97 & 17.75 & 1.77 & 171.68 & 12.19 & 57.36 \\
\hline
\end{tabular}

\section{Experimental Test Bench and Results}

\subsection{Apparatus Setup}

In this work, an apparatus was assembled to perform the experimental tests (Figure 11). In the laboratory, a three-phase squirrel cage induction motor of $7.5 \mathrm{~kW}$, four poles, $220 \mathrm{~V}$ line voltage and 60 $\mathrm{Hz}$ was used for rotor failure evaluation. A Hantek digital oscilloscope was used to collect the Hall sensor signal and a PC computer (i7 processor, 7th Gen Intel, 16 GB and Windows 10 was applied to store data. For oscillating load experiments an acquisition board has been used (National Instruments - NI-USB-6003).The load torque was applied in the induction motor with an eddy-current braking system. For non-sinusoidal tests, a WEG frequency converter (WEG Company, CFW 08 model in a switching frequency of $4 \mathrm{kHz}$ ) was used in an open-loop control approach $(\mathrm{V} / \mathrm{Hz}$ control).The rotor has 38 bars numbered among 1 and 38. This induction machine was manufactured to research purposes; thus, it is possible to connect and disconnect any rotor bar with the end-ring part using jumpers (Figure 12).

The Hall transducer manufacturer supplied the following information about the sensor: accuracy of $2 \%$ in $25^{\circ} \mathrm{C}$, operating temperature range between $-40{ }^{\circ} \mathrm{C}$ and $100{ }^{\circ} \mathrm{C}$, temperature coefficient of magnetic sensitivity equal to $-0.06 \% /{ }^{\circ} \mathrm{C}$ (max). The conversion of the transducer is $1 \mathrm{~T} / \mathrm{V}$ or $0.1 \mathrm{~T} / \mathrm{V}$ and the frequency response of the Hall sensor and its electronic transducer is $700 \mathrm{~Hz}$ of $0.1 \mathrm{~T} / \mathrm{V}$. 


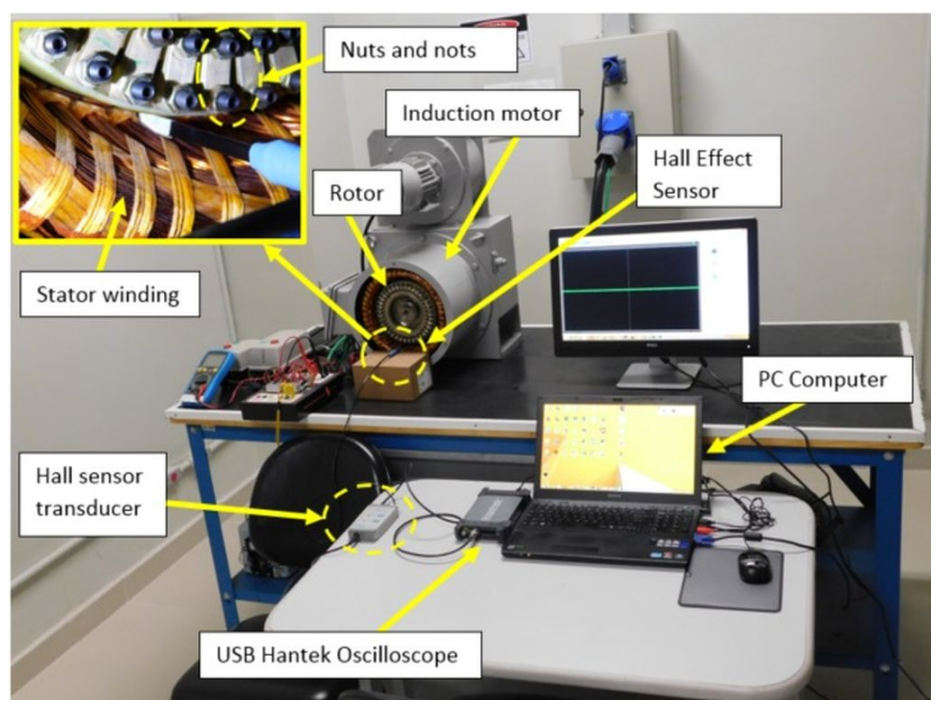

Figure 11. Apparatus setup.

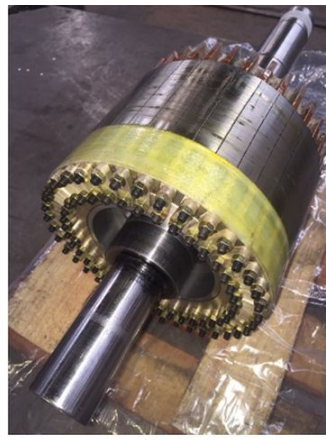

(a)

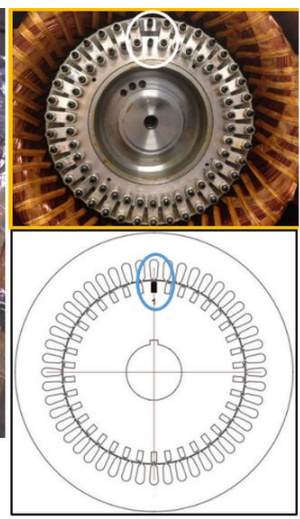

(b)

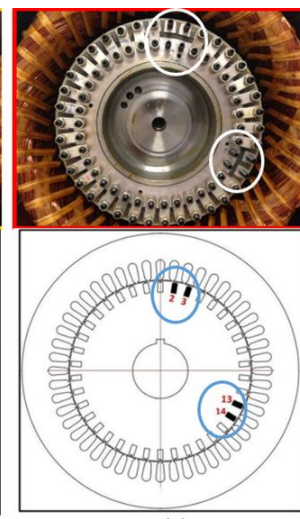

(c)

Figure 12. (a) rotor structure and bars connected with jumpers; (b) one fully broken bar (without jumpers) and (c) four fully broken bars (two broken bars in one magnetic pole and other two in the adjacent magnetic pole).

\subsection{Experimental Results and Discussion}

In this section, the results are presented and the methodology is discussed for motor fed by a direct line, i.e., with sinusoidal power supply and fed by an inverter.

\subsubsection{Rotor Condition Evaluation for Motors Running at Steady State Condition and Fed by a Sinusoidal Supply}

In this section, it has been performed a comparison between the disturbances found in the Hall effect sensor for a healthy rotor and a damaged one. A first dataset was built for an induction motor fed by direct line. As previously described, the resultant magnetic flux density in the air gap is defined from the currents that flows through each rotor bar. Therefore, in case of broken bars, disturbances in the resultant magnetic flux can be measured using the Hall sensor installed between the stator coils. In this case, the Hall signal was sampled at a frequency of $10 \mathrm{kHz}$ and a Butterworth sixth order low-pass filter was used in a cutoff frequency of $800 \mathrm{~Hz}$ to reduce the harmonic content. As mentioned before, after applying the zero-crossing step and the algorithm for inflection points detection, a fuzzy stage has been performed for feature extraction of each positive and negative half-cycle. The magnetic flux density collected from Hall sensor was normalized between -1 and +1 for each load torque condition. Figure 13a shows the peak signal distortion created due to rotor faults. In this case, it is possible to note the valley in the peak signal increases with the number of broken bars. Figure 13b 
shows the fuzzified valley severity for each positive half-cycle depicted by Figure 13a. It is clearly that the severity of the fault is related to the number of broken bars. These values and the statistical features extracted from each fuzzified valley were used as inputs for SVM classifier (Equation (7)). Table 6 shows the typical statistical values (fuzzified half-cyles) obtained for each rotor condition, considering only adjacent broken bars.

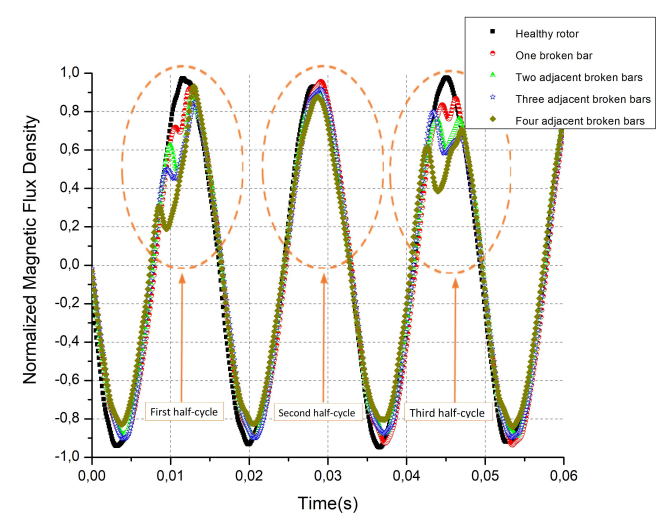

(a)

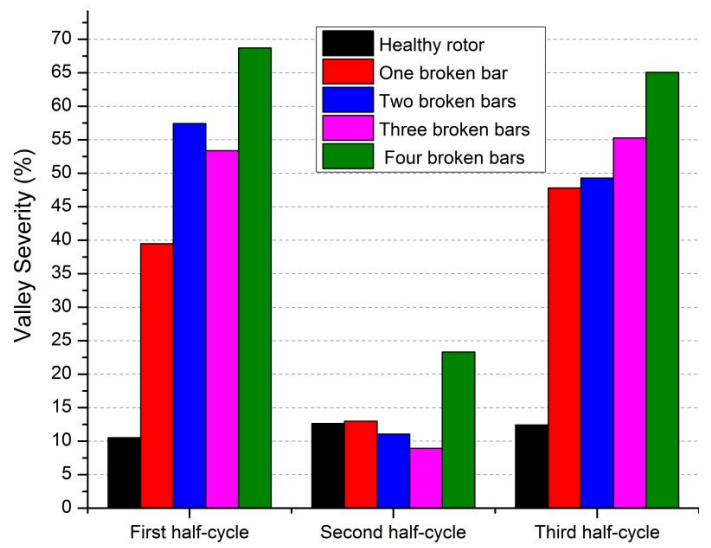

(b)

Figure 13. Experimental results of the magnetic flux density in a rated load torque (stead steady regime at slip $=1 \%$ ) for $7.5 \mathrm{~kW}$ induction motor showing: (a) flux disturbances near the air gap (Peak signal distortion (valley) for each rotor condition (positive half-cycles)) and (b) cycles after fuzzification stage (Fuzzified valley severity for each rotor condition).

Table 6. Comparison between some typical statistical data according to rotor conditions.

\begin{tabular}{lcccccc}
\hline \multicolumn{1}{c}{ Condition } & KUR & MEAN & SKW & $\sigma^{\mathbf{2}}$ & $\sigma$ & DFV \\
\hline Healthy (slip = 1.44\%) & $\mathbf{1 . 3 9}$ & $\mathbf{1 4 . 2 2}$ & $\mathbf{0 . 5 4}$ & $\mathbf{3 1 . 2 6}$ & $\mathbf{5 . 5 2}$ & $\mathbf{3 1 . 0 5}$ \\
1BB (slip = 1.44\%) & 5.29 & 18.72 & 1.9 & 46.97 & 6.81 & 44.34 \\
2BB (slip $=1.44 \%)$ & 4.83 & 20.92 & 1.84 & 125.77 & 11.15 & 62.42 \\
3BB (slip $=1.44 \%)$ & 5.19 & 16.2 & 2.05 & 149.54 & 12.17 & 60.39 \\
4BB (slip $=1.44 \%)$ & 1.64 & 24.45 & 1.12 & 213.33 & 14.57 & 67.47 \\
\hline
\end{tabular}

It is possible to note that all statistical values for a healthy rotor are smaller when compared to a rotor with broken bars. Although a healthy rotor does not produce valleys in the waveform, the eventual distortion in the signal is capable of generating some type of false valleys; thus, this peak value is not zero. However, the statistical values in a healthy rotor condition is substantially distinct from those found to other rotor cases. In addition, it is possible to observe that the variance, standard deviation and the valley severity are greater when the number of broken bars increases.

These values, including the root mean square, DFV and NVS, were used as inputs (Equation (7)) for the SVM classifier, after the creation of the knowledge base 1.

In this case, the knowledge base 1 was created with 57 motor operational scenarios, including a rotor speed between $1772 \mathrm{rpm}(\mathrm{slip}=1.5 \%)$ and $1742 \mathrm{rpm}(\mathrm{slip}=3.22 \%)$. The rated speed of the motor is $1740 \mathrm{rpm}$ (rated slip $=3.3 \%$ ). For training purposes, 42 scenarios with distinct rotor failures were used and 15 scenarios were applied for a validation step. An acquisition time of $4 \mathrm{~s}$ was used for collect the Hall sensor signal and each scenario was divided into eight time-windows (half a second).

A 10-fold (divisions) cross-validation step was applied during training step and the SVM classifiers have been designed in Matlab Classification Learner Toolbox. As mentioned by [39,53], the scores derived from the confusion matrix and the area under curve (AUC) of the receiver operating characteristic (ROC curve) can be used as performance metrics to select the optimal classifier tuning on each case. As mentioned by [53], an ROC curve is the resulting true positive rate (Sensitivity) against 
the false positive rate (Specificity) for different thresholds. Each point depicted in the ROC curve represents a sensitivity-specificity pair in a specific decision threshold. The more the ROC curve is to the upper left corner, the better the classifier performance is [53].

Table 7 shows the SVM evaluation after a cross validation step for three kernel functions and the best classifier selected according to the best value of accuracy. In this case, a cost tuning parameter equal to 10 was chosen in a range of 0 and 200, using an SVM classifier with a quadratic kernel function. This SVM structure has been applied for all motor operational scenarios. As mentioned, in this work, the SVM was used in a multiclass problem using a One Against One (OAO) approach.

Table 7. SVM evaluation after a cross validation step.

\begin{tabular}{lccc}
\hline Cost (C) & Kernel & Accuracy & AUC (ROC Curve) \\
\hline 1 & Quadratic & $89.6 \%$ & 1 \\
$\mathbf{1 0}$ & Quadratic & $\mathbf{9 0 . 5} \%$ & $\mathbf{1}$ \\
100 & Quadratic & $89.6 \%$ & 1 \\
200 & Quadratic & $86.1 \%$ & 1 \\
1 & Gaussian & $74 \%$ & 0.99 \\
10 & Gaussian & $89.3 \%$ & 1 \\
100 & Gaussian & $88.8 \%$ & 0.99 \\
200 & Gaussian & $88.8 \%$ & 0.99 \\
1 & Linear & $87.9 \%$ & 0.99 \\
10 & Linear & $89.3 \%$ & 0.99 \\
100 & Linear & $89.9 \%$ & 0.99 \\
200 & Linear & $89.6 \%$ & 0.99 \\
\hline
\end{tabular}

Figure 14 shows an ROC curve for validation cases using the best SVM quadratic classifier. It is important to highlight that the area under the curve is almost equalt to one (AUC $=0.967$ ); thus, the present approach was able to distinguish between a rotor fault and a healthy one. Table 8 shows the results obtained for other damaged rotor cases considering only adjacent broken bars. Table 9 shows the results obtained for other operational scenarios including cases with more than one and two broken bars per magnetic pole of the motor.

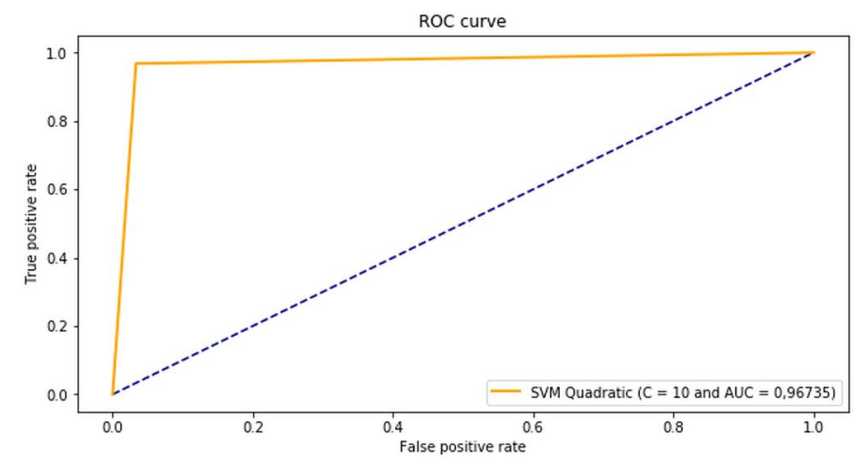

Figure 14. ROC curve for validation cases (healthy rotor and one broken bar).

Table 8. Classification results for each rotor condition (healthy and adjacent broken bars).

\begin{tabular}{cccc}
\hline \multicolumn{1}{c}{ Condition } & Desired Time Windows & SVM Output & Error(\%) \\
\hline Healthy (slip $=1.44 \%)$ & 32 & 31 & 3.125 \\
1BB (slip $=1.44 \%)$ & 8 & 8 & 0 \\
2BB (slip $=1.44 \%)$ & 8 & 8 & 0 \\
3BB (slip $=1.44 \%)$ & 8 & 6 & 25 \\
4BB (slip $=1.44 \%)$ & 8 & 7 & 12.5 \\
\hline
\end{tabular}


Table 9. Classification results for each rotor condition (healthy and nonadjacent broken bars).

\begin{tabular}{lccc}
\hline Condition & Desired Time Windows & SVM Output & Error(\%) \\
\hline Healthy & 32 & 31 & 3.125 \\
1BB & 24 & 23 & 4.16 \\
2BB & 32 & 20 & 37.5 \\
\hline
\end{tabular}

It is possible to note that, for adjacent cases, the SVM classifier was able to distinguish between a healthy rotor and more than one broken bar, considering a short acquisition time (equal to $0.25 \mathrm{~s}$ ) for Hall sensor signal. Even for nonadjacent broken bars, the SVM classifier has obtained good results also for an acquisition time equal to $0.25 \mathrm{~s}$.

\subsubsection{Rotor Condition Evaluation for Motor Running at Oscillating Load and Fed by} a Sinusoidal Supply

In this section, the rotor condition has been evaluated for motor running at oscillating loads and gradual load variation. In the first case, the motor was supplied by a direct line and a low-speed load oscillation was applied during the acquistion time (10 s), as shown in Figure 15a. The rotor is healthy, i.e., there is no broken bar, but the MCSA of the stator current shows two left sidebands, thus a potential case of false positive, as cited by [12].

The best SVM classifier selected from Table 7 was applied to this new operational condition of the motor to evaluate potential broken rotor bars. The Fuzzy-SVM approach has been tested on each time window of $0.5 \mathrm{~s}$ (out of $10 \mathrm{~s}$ ); thus, there were 20 time-windows for classification purposes. The SVM was able to sort all the values (output $=0$ ); thus, it performed a good classification, unlike the MCSA method (Figure 15b). In addition, it is important to highlight that it was not necessary to train the SVM classifier, although the learning step was performed only with steady-state values.

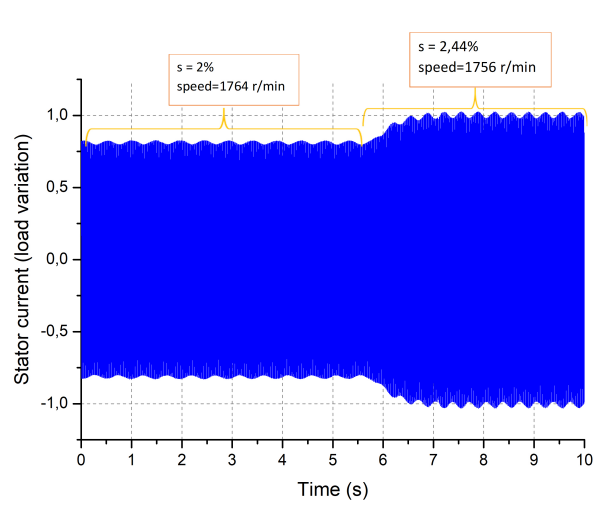

(a) Stator current variation

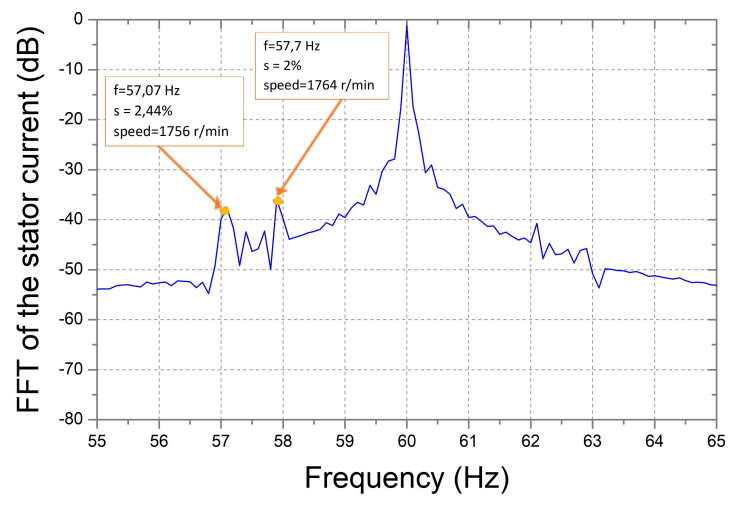

(b) Left sidebands due to the low-speed load oscillation

Figure 15. Experimental results for a healthy rotor in a time window of $10 \mathrm{~s}$, applying a low-speed load oscillation: (a) stator current variation; (b) motor Current Signature Analysis (MCSA).

Figure 16 shows the current stator with gradual load torque oscillation (1753-1772 r/min) and its MCSA spectrum. It is possible to note the sideband harmonics, even for a healhty rotor, also for an acquisition time of $10 \mathrm{~s}$. 


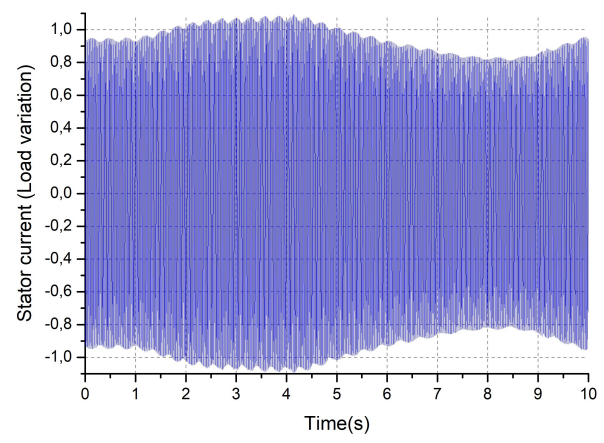

(a) Stator current variation

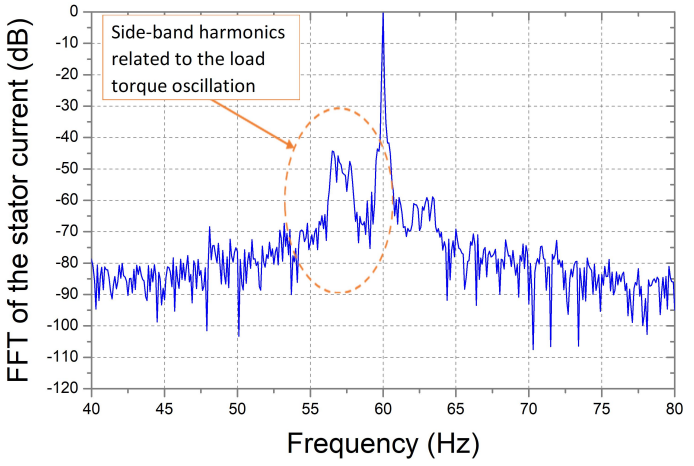

(b) MCSA of the stator current

Figure 16. Experimental results for a current stator with gradual load oscillation (1753-1772 r/min) in a time window of $10 \mathrm{~s}$ (healthy motor): (a) stator current variation; (b) motor current signature analysis (MCSA).

In the same way, an SVM classifier was applied to evaluate rotor condition and it was possible to sort again all output values without false indications. Figure $16 \mathrm{~b}$ shows the potential false positive condition due to the left sidebands. Figure 17a,b also depicted a potential false positive due the sidebands in a more frequent load oscillation (1749-1772 r/min). Again, the Fuzzy-SVM approach was applied in this case and it performed a good classification (four time-windows (half second) = 1 and 16 time-windows (half second $=0$ ).

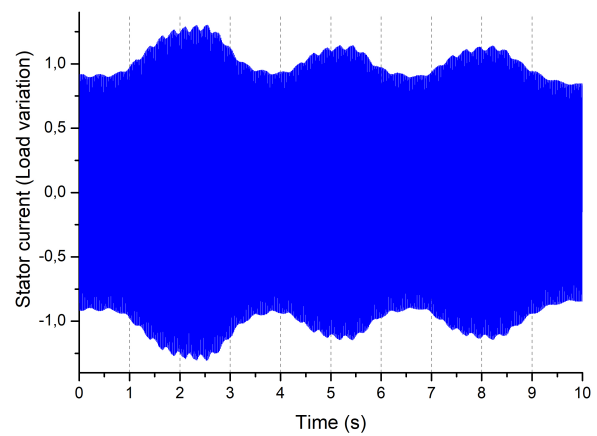

(a) Stator current variation

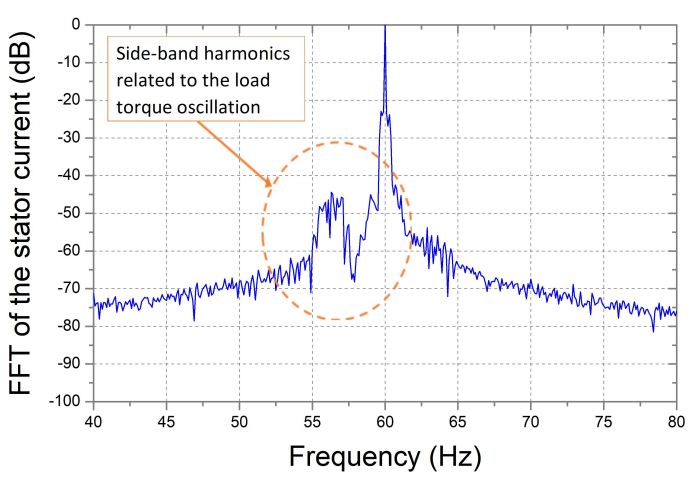

(b) MCSA of the stator current

Figure 17. Experimental results for a current stator with more frequent load oscillation (1749-1772 r/min) in a time window of $10 \mathrm{~s}$ (healthy motor): (a) stator current variation; (b) motor current signature analysis (MCSA) of the stator current.

Figure 18a,b show experimental results for a current stator and its MCSA spectrum with load oscillation (1745-1778 r/min) and one broken bar. In this case, Figure 18b may lead to a false negative condition, since there is a spectral leakage of the sideband harmonics due to load torque oscillation and it is difficult to estimate the correct rotor speed. By applying the Fuzzy-SVM approach, it was possible to find 14 time-windows related to the output $=1$ and six time-windows related to the output $=0$. As cited by [52], the use of a Bayesian classifier in this case can minimizes the misclassification error. The following section shows the results for a motor fed by an inverter. 


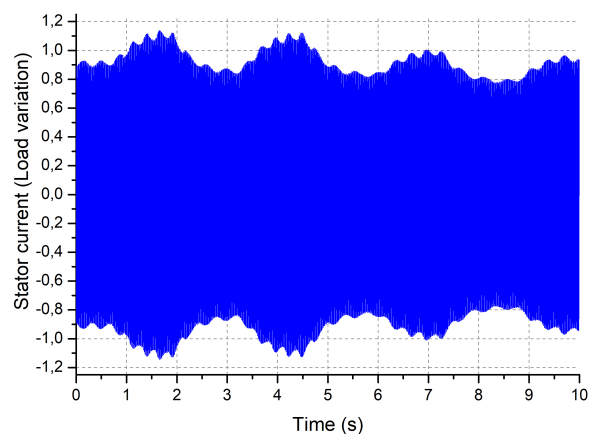

(a) Stator current variation

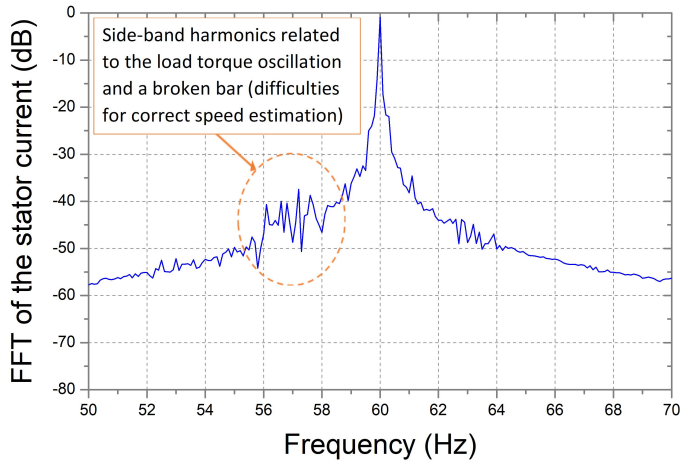

(b) MCSA of the stator current

Figure 18. Experimental results for a current stator with more frequent load oscillation (1745-1778 r/min) in a time window of $10 \mathrm{~s}$ (one broken bar): (a) stator current variation; (b) motor current signature analysis (MCSA) of the stator current.

In Table 10 is shown a comparison between the fuzzy statistical parameters for each condition. For a low-speed load oscillation, the values are quite similar to those found for a typical healthy case. However, when the oscillating frequency increases, the values become more similar to those found by a faulted rotor. Therefore, a threshold value should be investigated to apply the Bayesian classification and avoid false indications.

Table 10. Comparison between some typical statistical data according to rotor conditions for oscillating loads.

\begin{tabular}{lcccccc}
\hline \multicolumn{1}{c}{ Condition } & KUR & MEAN & SKW & $\sigma^{2}$ & $\sigma$ & DFV \\
\hline Healthy motor (Low-speed oscillation (slip $=\mathbf{2} \%$ and slip = 2.44\%)) & $\mathbf{1 . 2 4}$ & $\mathbf{1 1 . 7 6}$ & $\mathbf{0 . 5 6}$ & $\mathbf{2 9 . 0 3}$ & $\mathbf{5 . 3 4}$ & $\mathbf{2 7 . 6 1}$ \\
Healthy motor (slip $=2.61 \%$ and slip $=1.55 \%)$ & 3.41 & 14.49 & 1.01 & 46.51 & 6.64 & 38.36 \\
Healthy motor (slip $=2.83 \%$ and slip $=1.55 \%)$ & 2.32 & 14.74 & 0.91 & 55.23 & 7.22 & 38.19 \\
One broken bar (slip $=3.05 \%$ and slip $=1.22 \%)$ & 2.33 & 15.71 & 1.16 & 77.72 & 8.76 & 43 \\
\hline
\end{tabular}

\subsubsection{Rotor Condition Evaluation for a Motor Fed by an Inverter}

This section shows the SVM performance evaluation for rotor condition detection for induction motor fed by an inverter. A knowledge base 2 was created after the signal processing stage and feature extraction stage using fuzzy logic, similar to procedures executed to the knowledge base 1 (sinusoidal case). For each piece of experimental data, a time window (acquisition time) of $10 \mathrm{~s}$ was used for processing. Each time window was divided into lower time windows equal to $0.5 \mathrm{~s}$; thus, each test produces 20 datasets. In this work, a total of 1200 time windows of $0.5 \mathrm{~s}$ (60 experiments) were used for SVM learning step and 700 time windows of $0.5 \mathrm{~s}$ (35 experiments) were used for validation purposes.

For performance evaluation of SVM, a cross validation (CV) step was used with 10-fold (k divisions). The SVM was also implemented and tested in the Classification Learner toolbox of the Matlab sotware. In addition, the receiver operating characteristic (ROC curve) and the area under the curve were also used to evaluate the classifier metrics. It is important to highlight that the database has considered the experiments for motor running in three rotor conditions (healthy, one broken bar and three adjacent broken bars) and fed by an inverter. In Figure 19, it is possible to note the valley in the normalized magnetic flux density for each rotor condition. 


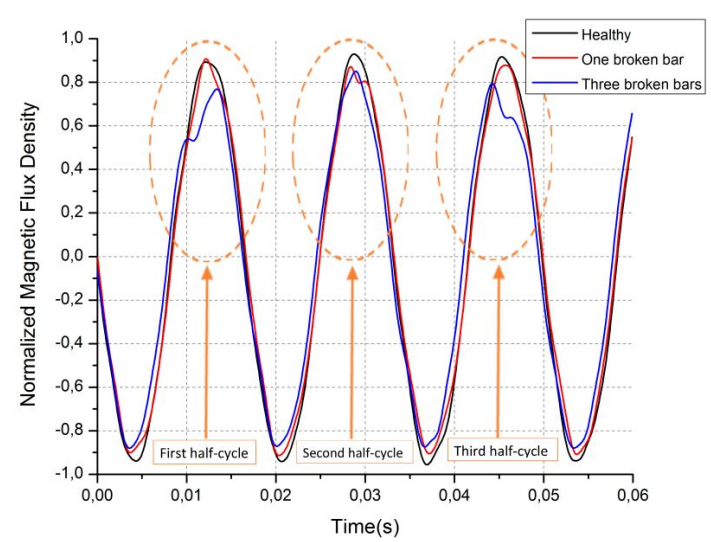

(a)

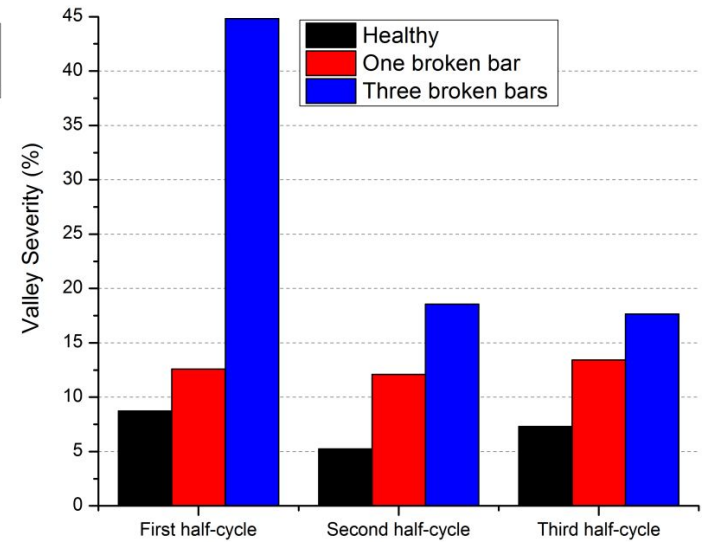

(b)

Figure 19. Experimental results of the magnetic flux density in stead steady regime for $7.5 \mathrm{~kW}$ induction motor fed by an inverter: (a) flux disturbances near the air gap (Peak signal distortion (valley) for each rotor condition (positive half-cycles)) and (b) cycles after fuzzification stage (fuzzified valley severity for each rotor condition).

The fuzzified valley severity for each rotor condition depicted by Figure 19a was shown in Figure 19b. It is possible to clearly note the differences between the severity for a healthy rotor and a damaged one. In Table 11, the typical fuzzy statistical data are shown according to each rotor condition and the differences between them in a time window of $0.5 \mathrm{~s}$. For a healthy rotor, there are lower values when compared to cases with one and three broken bars. These values were also used as inputs for the SVM classifier, such as the implementation carried out in the sinusoidal case.

Table 11. Comparison between some median statistical data according to rotor conditions.

\begin{tabular}{lcccccc}
\hline Condition & KUR & MEAN & SKW & $\sigma^{\mathbf{2}}$ & $\sigma$ & DFV \\
\hline Healthy & $\mathbf{1 . 8 4}$ & $\mathbf{1 5 . 0 1}$ & $\mathbf{0 . 5 1 1}$ & $\mathbf{2 2 . 3 1}$ & $\mathbf{4 . 6 6}$ & $\mathbf{2 9 . 4 4}$ \\
1BB & 2.42 & 15.67 & 1.1 & 42.23 & 6.45 & 37.89 \\
3BB & 1.86 & 20.54 & 1.23 & 158.07 & 12.54 & 59.77 \\
\hline
\end{tabular}

In Table 12, the data obtained for SVM classifier were presented and the structure with quadratic kernel function and cost parameter value equal to 1 was the best one. The accuracy during learning step achieved $97.1 \%$ and AUC $=0.99$, for all three classes (healthy, one broken bar and three broken bars); thus, a good performance for broken bar diagnosis and fault severity evaluation.

Table 12. SVM evaluation after cross validation step.

\begin{tabular}{lccc}
\hline Cost (C) & Kernel & Accuracy & AUC(ROC Curve) \\
\hline $\mathbf{1}$ & Quadratic & $\mathbf{9 7 . 1} \%$ & $\mathbf{0 . 9 9}$ \\
10 & Quadratic & $96.3 \%$ & 0.99 \\
100 & Quadratic & $96.7 \%$ & 0.99 \\
200 & Quadratic & $96.8 \%$ & 0.99 \\
1 & Gaussian & $95.3 \%$ & 0.98 \\
10 & Gaussian & $96.5 \%$ & 0.99 \\
100 & Gaussian & $94.8 \%$ & 0.98 \\
200 & Gaussian & $94.5 \%$ & 0.98 \\
1 & Linear & $96.6 \%$ & 0.99 \\
10 & Linear & $96.5 \%$ & 0.99 \\
100 & Linear & $96.6 \%$ & 0.98 \\
200 & Linear & $96.7 \%$ & 0.98 \\
\hline
\end{tabular}


Figure 20 shows the ROC curve and the AUC for the best SVM classifier considering two classes, i.e., a healthy rotor and one broken bar. It is possible to note that, in this case, the AUC is almost 1 $(\mathrm{AUC}=0.962)$,

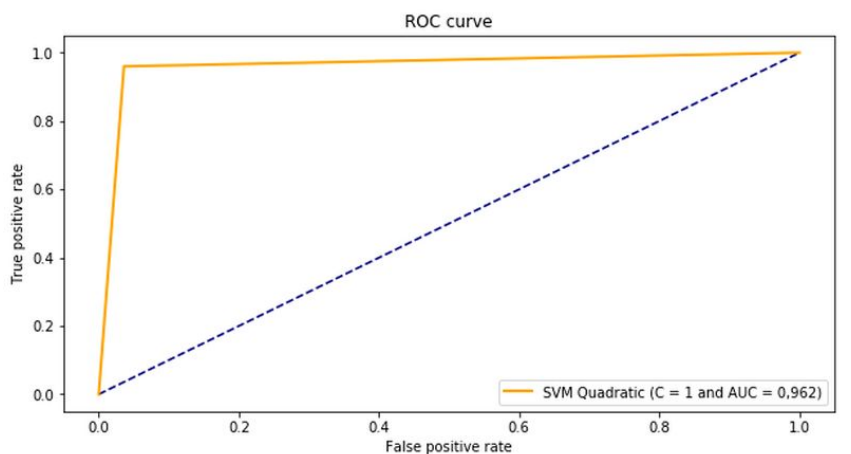

Figure 20. ROC curve for validation cases (healthy rotor and one broken bar).

The classification results for each rotor condition are shown in Table 13. These results are related to the classification of 700 sample windows of $0.5 \mathrm{~s}$ (35 experiments), including the three classes (healthy, $1 \mathrm{BB}$ and $3 \mathrm{BB})$. The SVM classifier was able to distinguish more than $96 \%$ of validation cases.

Table 13. Classification results for each rotor condition (inverter-fed mode).

\begin{tabular}{lccc}
\hline Condition & Desired Time Windows & SVM Output & Error(\%) \\
\hline Healthy & $300(15$ exps $)$ & 289 & 3.66 \\
1BB & $220(11$ exps $)$ & 212 & 3.63 \\
3BB & $180(9$ exps) & 180 & 0 \\
Total & 700 (35 experiments) & $\mathbf{6 8 1}$ & $\mathbf{2 . 7 1}$ \\
\hline
\end{tabular}

4.2.4. Rotor Condition Evaluation for Motor Fed by an Inverter and Running at Steady State Condition and Oscillating Loads

This subsection shows the Fuzzy-SVM performance evaluation for induction motor fed by an inverter and running at oscillating loads. Figure 21a,b show the MCSA applied to the healthy motor running at steady-state condition $(1771 \mathrm{r} / \mathrm{min})$. In this case, it is possible to observe additional harmonics in the frequency spectrum due to the converter mode and the potential false positive evaluation for rotor cage diagnosis.

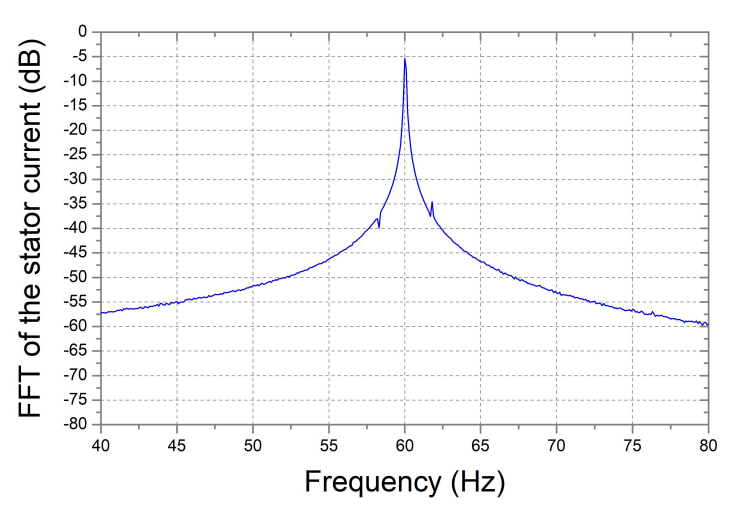

(a) MCSA of a motor fed by line

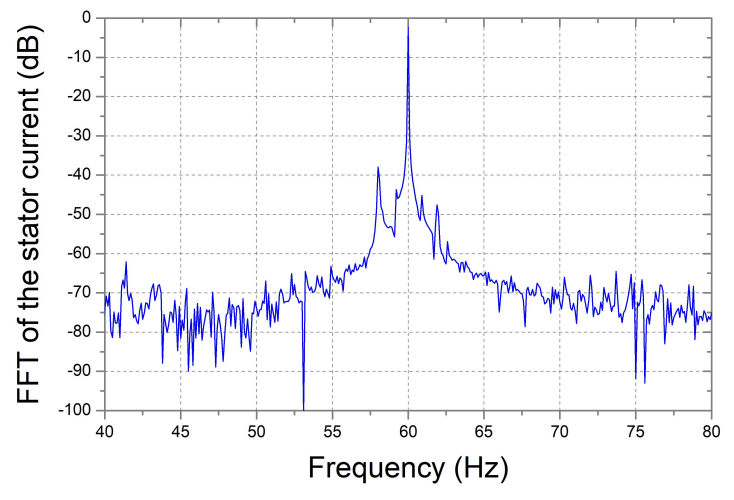

(b) MCSA of a motor fed by an inverter

Figure 21. Experimental results for a motor running at steady-state $(1771 \mathrm{r} / \mathrm{min}$ ) (healthy motor): (a) motor current signature analysis (MCSA) for motor direct-line supplied; (b) motor current signature analysis (MCSA) for motor in inverter-fed mode. 
Figure 22a shows the stator current variation for a motor running at low-speed load oscillation (1748 r/min-1758 r/min). Figure 22b shows the MCSA applied to the stator current and two left sidebands generated by load oscillation. Although there is a healthy case, an incorrect interpretation of this condition can lead to a false positive diagnosis.

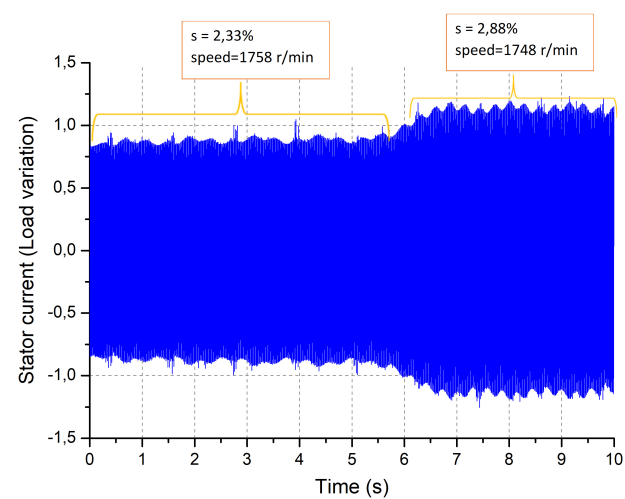

(a) Stator current variation

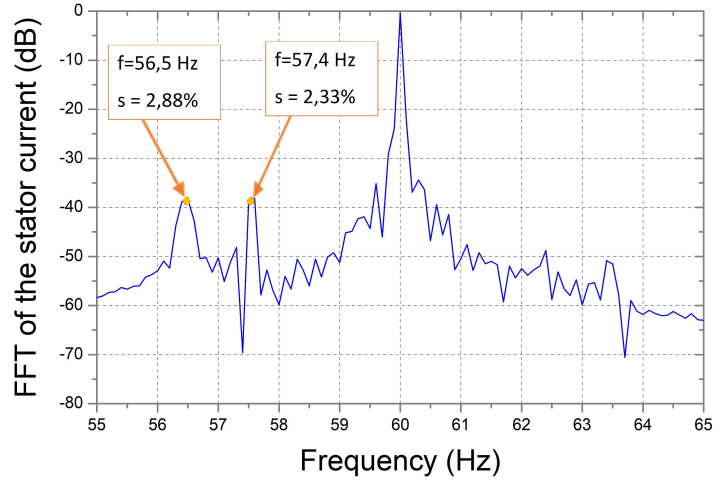

(b) Motor Current Signature Analysis (MCSA)

Figure 22. Experimental results for a motor running at low-speed load oscillation (1748-1758 r/min) in a time window of $10 \mathrm{~s}$ (healthy motor): (a) stator current variation; (b) motor current signature analysis (MCSA) of the stator current.

Figure 23a,b show a more frequent load oscillation, when compared to the previous case. Again, the the MCSA method has demonstrated the potential for a false positive evaluation, due to the sideband frequencies generated by load torque oscillation. On the other hand, Figure $24 \mathrm{a}, \mathrm{b}$ show a faulted rotor case (one broken bar) for a low-speed load oscillation case. It is possible to note the sidebands harmonics related to the load torque oscillation and an incorrect slip estimation can lead to a false negative rotor evaluation.

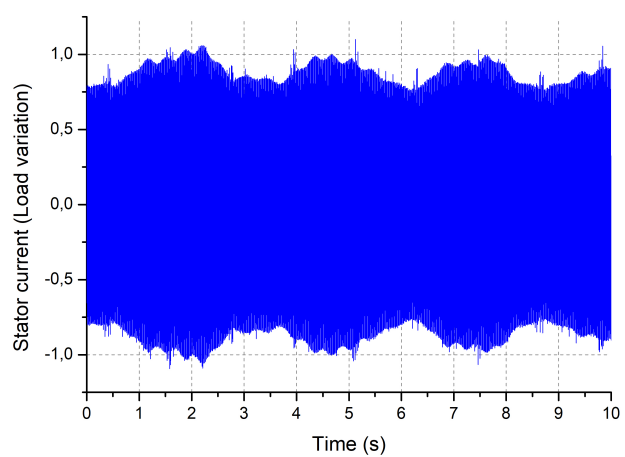

(a) Stator current variation

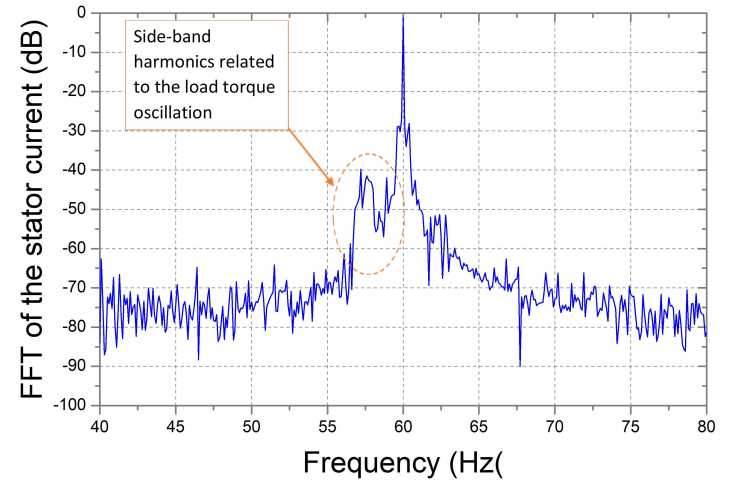

(b) Motor Current Signature Analysis (MCSA)

Figure 23. Experimental results for a motor running at load oscillation in a time window of $10 \mathrm{~s}$ (healthy motor): (a) stator current variation; (b) motor current signature analysis (MCSA) of the stator current. 


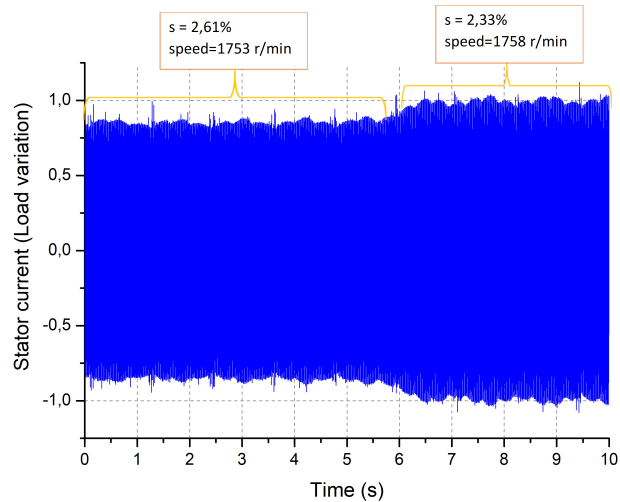

(a) Stator current variation

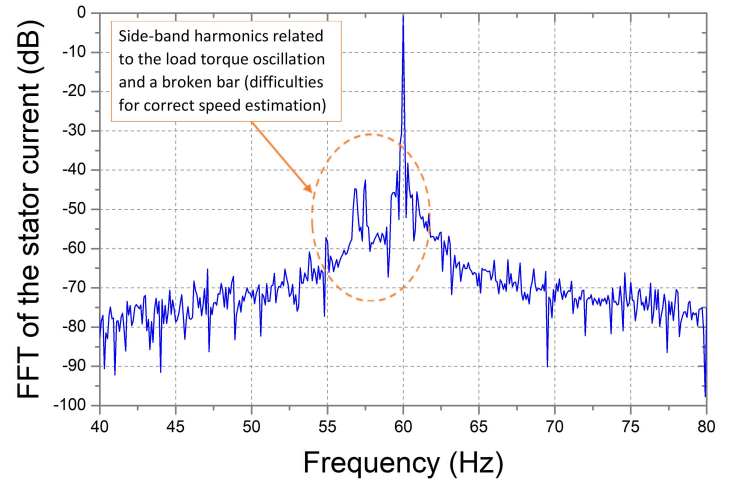

(b) Motor Current Signature Analysis (MCSA)

Figure 24. Experimental results for a motor running at low-speed load oscillation (1753-1758 r/min) in a time window of $10 \mathrm{~s}$ (one broken bar): (a) stator current variation; (b) motor current signature analysis (MCSA) of the stator current.

Based on the aforementioned operational scenarios, the MCSA technique is very limited for rotor cage evaluation, considering the load variation and/or load oscillation applications. For the simulation and experimental cases, the present Fuzzy-SVM approach has achieved a good performance as shown in Table 14.

Figure 25 summarizes the results for both the sinusoidal and inverter-fed modes. In general, the SVM classification results for a motor fed by an inverter were better than those found by a sinusoidal case, but these results should be credited to the greater volume of data used during the learning step in inverter mode, when compared to those used in a direct line mode. However, in all cases, it was possible to note that the Fuzzy-SVM approach was able not only do detect the motor fault but also to evaluate its severity with good accuracy.

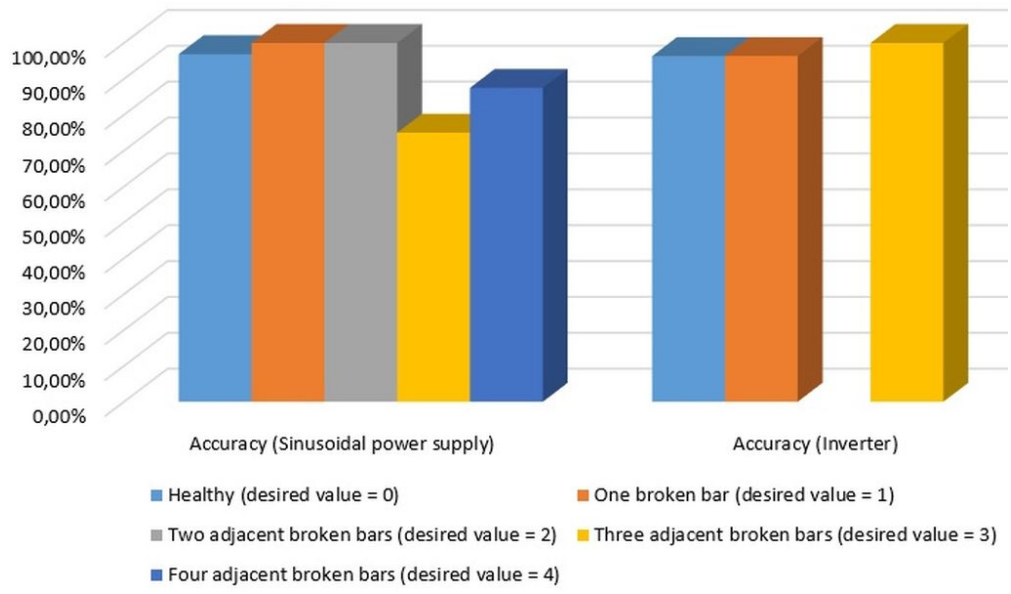

Figure 25. Accuracy for each rotor condition and motor power supply. 
Table 14. Classification results using the Fuzzy-SVM approach for different operational scenarios.

\begin{tabular}{|c|c|c|}
\hline Motor/Operational Scenario & Desired Output & Fuzzy-SVM Output \\
\hline $1200 \mathrm{~kW} 6$ poles IM/Healthy (steady state at slip $=0.91 \%$ )-SIMULATED SCENARIO & $\mathbf{0}$ & $\mathbf{0}$ \\
\hline $1200 \mathrm{~kW} 6$ poles IM/Healthy (oscillating load in the slip range of $0.87 \%$ to $0.93 \%$ )-SIMULATED SCENARIO & 0 & $\mathbf{0}$ \\
\hline $1200 \mathrm{~kW} 6$ poles IM/Healthy (oscillating load in the slip range of $0.84 \%$ to $0.97 \%$ )-SIMULATED SCENARIO & 0 & 0 \\
\hline $1200 \mathrm{~kW} 6$ poles IM/1BB (steady state at slip = 0.91\%)-SIMULATED SCENARIO & 1 & 1 \\
\hline $1200 \mathrm{~kW} 6$ poles IM/1BB (load variation in two slips $(0.44 \%$ and $0.91 \%)$ )-SIMULATED SCENARIO & 1 & 1 \\
\hline $1200 \mathrm{~kW} 6$ poles IM/1BB ((oscillating load in the slip range of $0.88 \%$ to $0.91 \%))$-SIMULATED SCENARIO & 1 & 1 \\
\hline $1200 \mathrm{~kW} 6$ poles IM/1BB ((oscillating load in the slip range of $0.87 \%$ to $0.93 \%))$-SIMULATED SCENARIO & 1 & 1 \\
\hline $1200 \mathrm{~kW} 6$ poles IM/1BB ((oscillating load in the slip range of $0.84 \%$ to $0.97 \%)$ )-SIMULATED SCENARIO & 1 & 0 \\
\hline $1200 \mathrm{~kW} 6$ poles IM/2BB (steady state at slip = 0.91\%)-SIMULATED SCENARIO & 2 & 3 \\
\hline $7.5 \mathrm{~kW} 4$ poles IM/Healthy (steady state at slip $=0.92 \%$ )-SIMULATED SCENARIO & 0 & $\mathbf{0}$ \\
\hline $7.5 \mathrm{~kW} 4$ poles IM/Healthy (oscillating load in the slip range of $2.6 \%$ to $2.8 \%$ )-SIMULATED SCENARIO & 0 & $\mathbf{0}$ \\
\hline $7.5 \mathrm{~kW} 4$ poles IM/1BB (steady state at slip $=0.92 \%$ )-SIMULATED SCENARIO & 1 & 1 \\
\hline $7.5 \mathrm{~kW} 4$ poles IM/1BB ((oscillating load in the slip range of $2.6 \%$ to $2.8 \%$ ))-SIMULATED SCENARIO & 1 & 2 \\
\hline $7.5 \mathrm{~kW} 5$ poles IM/2BB (steady state at slip = 0.92\%)-SIMULATED SCENARIO & 2 & 2 \\
\hline $7.5 \mathrm{~kW} 4$ poles IM/Healthy (low-speed load oscillation-slip $=2 \%$ to $2.44 \%$ )- EXP. SCENARIO (Figure 15 ) & 0 & $\mathbf{0}$ \\
\hline $7.5 \mathrm{~kW} 4$ poles IM/Healthy (gradual load oscillation-1753 to $1772 \mathrm{r} / \mathrm{min}$ )-EXP. SCENARIO (Figure 16) & 0 & $\mathbf{0}$ \\
\hline $7.5 \mathrm{~kW} 4$ poles IM/Healthy (frequent load oscillation-1749 to $1772 \mathrm{r} / \mathrm{min}$ )-EXP. SCENARIO (Figure 17) & 0 & 0 \\
\hline $7.5 \mathrm{~kW} 4$ poles IM/1BB (frequent load oscillation-1745 to $1778 \mathrm{r} / \mathrm{min}$ )-EXP.SCENARIO (Figure 18) & 1 & 1 \\
\hline $7.5 \mathrm{~kW} 4$ poles IM/Healthy (low-speed load oscillation-1748 to $1758 \mathrm{r} / \mathrm{min}$ )-EXP.SCENARIO (Figure 22) & 0 & 0 \\
\hline $7.5 \mathrm{~kW} 4$ poles IM/Healthy (frequent load oscillation)-EXP.SCENARIO (Figure 23) & 0 & 0 \\
\hline $7.5 \mathrm{~kW} 4$ poles IM/1BB (frequent load oscillation)-EXP.SCENARIO (Figure 24) & 1 & 1 \\
\hline
\end{tabular}




\section{Conclusions}

This paper proposes a fuzzy-based approach to extract features from a Hall effect sensor signal to detect air gap disturbances, in a large squirrel cage induction motor with fully broken bars. In this method, some fuzzy statistical features were used as inputs for a support vector machine classifier to detect and classify the severity of rotor faults in an induction motor fed by a line and an inverter. This particular analysis is related to the inflection points detected for each positive and negative half-cycle, due to the broken bars and the existence of valleys when broken bars are near the sensor. Therefore, the fuzzy inference mechanism was able to evaluate the severity of a rotor fault, by using only one inflection point-in this case, the minimum amplitude, determined from two maximum points in the valley. It should be noted that the present solution requires an algorithm with low computational burden, since fuzzy logic usually has a non-complex implementation in software environments.

For a motor fed by line an acquisition time of $4 \mathrm{~s}$ was applied and each experiment was divided into segments of $0.5 \mathrm{~s}$. In the case of motor fed by an inverter, an acquisition time of $10 \mathrm{~s}$ was used and each experiment was also divided into segments of $0.5 \mathrm{~s}$. Therefore, the validation experiments were tested on each segment with good accuracy ( $>96 \%$ ) for broken bars detection and severity classification.

The main contributions of this work can be summarized as follows:

(i) It is not necessary to estimate rotor slip, as required by the MCSA method and other techniques; thus, this condition avoids FN indications;

(ii) It was possible to detect broken bars during load variation, again avoiding FN indications using the MCSA technique, although the increase of oscillations can lead to false diagnosis;

(iii) The Fuzzy-SVM approach achieved a good performance to detect broken bars during low-speed load oscillations, since this operational condition can lead to false positive evaluation;

(iv) It is possible to classify the damaged rotor severity, but further investigations should be made to improve this classification for load oscillation applications;

(v) This method is capable of detecting broken rotor bars for motor running at low slip; and

(vi) The proposed method requires a low-cost Hall effect sensor to measure air gap flux.

Although the noninvasive approaches are widely used in motor fault diagnosis field, the present method allows the rotor condition evaluation not only for new large induction machines, but also for those undergoing rewind processes. On the other hand, the present method requires a minimum load torque to produce the valley and perform the broken bars detection; thus, new improvements should be made to apply this approach at no-load or very low slip conditions. By using the simulation results, for example, it was possible to detect only one broken bar out of 104 bars (1200 kW induction motor); thus, this approach has achieved a good fault detection sensitivity. Further research should be conducted to assess the rotor faults at variable speeds and also to implement this fuzzy-SVM algorithm in a hardware capable of developing a robust tool for broken bars diagnosis.

Author Contributions: L.C.d.S. conceived and designed the experiments, and revised the manuscript; C.G.D. designed, tested the fuzzy statistical models and wrote the manuscript and I.E.C. analyzed the data and also wrote the manuscript.

Funding: This research was funded by Sao Paulo Research Foundation (FAPESP), Grant Nos. 2018/05214-2 and 2016/02525-1.

Acknowledgments: The authors are thankful to the Sao Paulo Research Foundation (FAPESP), Grant Nos. 2018/05214-2 and 2016/02525-1, and Nove de Julho University (UNINOVE) for their support.

Conflicts of Interest: The authors declare no conflict of interest.

\section{References}

1. Bonnett, A.H.; Soukup, G.C. Cause and analysis of stator and rotor failures in three-phase squirrel-cage induction motors. IEEE Trans. Ind. Appl. 1992, 28, 921-937. [CrossRef] 
2. Group, M.R.W. Report of large motor reliability survey of industrial and commercial installations, part II. IEEE Trans. Ind. Appl. 1985, 23, 153-158.

3. Group, M.R.W. Report of large motor reliability survey of industrial and commercial installations, part III. IEEE Trans. Ind. Appl. 1985, 21, 865-872.

4. Thorsen, O.V.; Dalva, M. Failure identification and analysis for high-voltage induction motors in the petrochemical industry. IEEE Trans. Ind. Appl. 1999, 35, 810-818. [CrossRef]

5. Antonino-Daviu, J.A.; Quijano-López, A.; Rubbiolo, M.; Climente-Alarcon, V. Advanced Analysis of Motor Currents for the Diagnosis of the Rotor Condition in Electric Motors Operating in Mining Facilities. IEEE Trans. Ind. Appl. 2018, 54, 3934-3942. [CrossRef]

6. Orlowska-Kowalska, T.; Dybkowski, M.; Kowalski, C.T. Fault-Diagnosis and Fault-Tolerant-Control in Industrial Processes and Electrical Drives. In Advanced Control of Electrical Drives and Power Electronic Converters; Springer: Cham, Switzerland, 2017; pp. 101-120.

7. Bellini, A.; Filippetti, F.; Tassoni, C.; Capolino, G.A. Advances in diagnostic techniques for induction machines. IEEE Trans. Ind. Electron. 2008, 55, 4109-4126. [CrossRef]

8. Zhang, P.; Du, Y.; Habetler, T.G.; Lu, B. A survey of condition monitoring and protection methods for medium-voltage induction motors. IEEE Trans. Ind. Appl. 2011, 47, 34-46. [CrossRef]

9. Magdaleno, J.R. Vibration analysis of partially damaged rotor bar in induction motor under different load condition using DWT. Shock Vib. 2016, 1-11. [CrossRef]

10. Sizov, G.Y.; Sayed-Ahmed, A.; Yeh, C.C.; Demerdash, N.A. Analysis and diagnostics of adjacent and nonadjacent broken-rotor-bar faults in squirrel-cage induction machines. IEEE Trans. Ind. Electron. 2009, 56, 4627-4641. [CrossRef]

11. Riera-Guasp, M.; Cabanas, M.F.; Antonino-Daviu, J.A.; Pineda-Sánchez, M.; García, C.H.R. Influence of nonconsecutive bar breakages in motor current signature analysis for the diagnosis of rotor faults in induction motors. IEEE Trans. Energy Convers. 2010, 25, 80-89. [CrossRef]

12. Lee, S.B.; Hyun, D.; Kang, T.J.; Yang, C.; Shin, S.; Kim, H.; Park, S.; Kong, T.S.; Kim, H.D. Identification of False Rotor Fault Indications Produced by Online MCSA for Medium-Voltage Induction Machines. IEEE Trans. Ind. Appl. 2016, 52, 729-739. [CrossRef]

13. Kral, C.; Kapeller, H.; Gragger, J.V.; Haumer, A.; Kubicek, B. Phenomenon Rotor Fault-Multiple Electrical Rotor Asymmetries in Induction Machines. IEEE Trans. Power Electron. 2010, 25, 1124-1134. [CrossRef]

14. Jung, J.; Lee, J.; Kwon, B. Online Diagnosis of Induction Motors Using MCSA. IEEE Trans. Ind. Electron. 2006, 53, 1842-1852. [CrossRef]

15. Benbouzid, M.E.H. A review of induction motors signature analysis as a medium for faults detection. IEEE Trans. Ind. Electron. 2000, 47, 984-993. [CrossRef]

16. Bellini, A.; Filippetti, F.; Franceschini, G.; Tassoni, C.; Passaglia, R.; Saottini, M.; Tontini, G.; Giovannini, M.; Rossi, A. On-field experience with online diagnosis of large induction motors cage failures using MCSA. IEEE Trans. Ind. Appl. 2002, 38, 1045-1053. [CrossRef]

17. Puche-Panadero, R.; Pineda-Sanchez, M.; Riera-Guasp, M.; Roger-Folch, J.; Hurtado-Perez, E.; Perez-Cruz, J. Improved resolution of the MCSA method via Hilbert transform, enabling the diagnosis of rotor asymmetries at very low slip. IEEE Trans. Energy Convers. 2009, 24, 52-59. [CrossRef]

18. Xu, B.; Sun, L.; Xu, L.; Xu, G. Improvement of the Hilbert method via ESPRIT for detecting rotor fault in induction motors at low slip. IEEE Trans. Energy Convers. 2013, 28, 225-233. [CrossRef]

19. Dias, C.G.; de Sousa, C. An experimental approach for diagnosis of adjacent and nonadjacent broken bars in induction motors at very low slip. In Proceedings of the IEEE International Electric Machines and Drives Conference (IEMDC), Miami, FL, USA, 21-24 May 2017; pp. 1-6.

20. Sapena-Bano, A.; Pineda-Sanchez, M.; Puche-Panadero, R.; Martinez-Roman, J.; Kanović, Ž. Low-cost diagnosis of rotor asymmetries in induction machines working at a very low slip using the reduced envelope of the stator current. IEEE Trans. Energy Convers. 2015, 30, 1409-1419. [CrossRef]

21. Orlowska-Kowalska, T.; Dybkowski, M.; Kowalski, C.T. Rotor fault analysis in the sensorless field oriented controlled induction motor drive. Autom. J. Control Meas. Electron. Comput. Commun. 2010, 51, 149-156. [CrossRef] 
22. Pons-Llinares, J.; Morinigo-Sotelo, D.; Duque-Perez, O.; Antonino-Daviu, J.; Perez-Alonso, M. Transient detection of close components through the chirplet transform: Rotor faults in inverter-fed induction motors. In Proceedings of the IECON 2014-40th Annual Conference of the IEEE Industrial Electronics Society, Dallas, TX, USA, 29 October-1 November 2014; pp. 3386-3392.

23. Delgado-Arredondo, P.A.; Morinigo-Sotelo, D.; Osornio-Rios, R.A.; Avina-Cervantes, J.G.; Rostro-Gonzalez, H.; de Jesus Romero-Troncoso, R. Methodology for fault detection in induction motors via sound and vibration signals. Mech. Syst. Signal Process. 2017, 83, 568 - 589. [CrossRef]

24. Nemec, M.; Ambrožič, V.; Fišer, R.; Nedeljković, D.; Drobnič, K. Induction Motor Broken Rotor Bar Detection Based on Rotor Flux Angle Monitoring. Energies 2019, 12, 794. [CrossRef]

25. Angelo, C.H.D.; Bossio, G.R.; Garcia, G.O. Discriminating broken rotor bar from oscillating load effects using the instantaneous active and reactive powers. IET Electr. Power Appl. 2010, 4, 281-290. [CrossRef]

26. Morinigo-Sotelo, D.; Garcia-Escudero, L.A.; Duque-Perez, O.; Perez-Alonso, M. Practical Aspects of Mixed-Eccentricity Detection in PWM Voltage-Source-Inverter-Fed Induction Motors. IEEE Trans. Ind. Electron. 2010, 57, 252-262. [CrossRef]

27. Yahia, K.; Cardoso, A.J.M.; Zouzou, S.E.; Gueddidi, S. Broken rotor bars diagnosis in an induction motor fed from a frequency converter: experimental research. Int. J. Syst. Assur. Eng. Manag. 2012, 3, 40-46. [CrossRef]

28. Kowalski, C.T.; Wierzbicki, R.; Wolkiewicz, M. Stator and rotor faults monitoring of the inverter-fed induction motor drive using state estimators. Automatika 2013, 54, 348-355. [CrossRef]

29. Antonino-Daviu, J.; Corral-Hernandez, J.; Climente-Alarcón, V.; Razik, H. Case stories of advanced rotor assessment in field motors operated with soft-starters and frequency converters. In Proceedings of the IECON 2015-41st Annual Conference of the IEEE Industrial Electronics Society, Yokohama, Japan, 9-12 November 2015; pp. 1139-1144.

30. Godoy, W.F.; da Silva, I.N.; Goedtel, A.; Palácios, R.H.C.; Lopes, T.D. Application of intelligent tools to detect and classify broken rotor bars in three-phase induction motors fed by an inverter. IET Electr. Power Appl. 2016, 10, 430-439. [CrossRef]

31. Romero-Troncoso, R.; Garcia-Perez, A.; Morinigo-Sotelo, D.; Duque-Perez, O.; Osornio-Rios, R.; Ibarra-Manzano, M. Rotor unbalance and broken rotor bar detection in inverter-fed induction motors at start-up and steady-state regimes by high-resolution spectral analysis. Electr. Power Syst. Res. 2016, 133, 142-148. [CrossRef]

32. el Malek, M.A.; Abdelsalam, A.K.; Hassan, O.E. Induction motor broken rotor bar fault location detection through envelope analysis of start-up current using Hilbert transform. Mech. Syst. Signal Process. 2017, 93, 332-350. [CrossRef]

33. Thomson, W.T.; Fenger, M. Industrial application of current signature analysis to diagnose faults in 3-phase squirrel cage induction motors. In Proceedings of the Conference Record of 2000 Annual Pulp and Paper Industry Technical Conference, Atlanta, GA, USA, 19-23 June 2000; pp. 205-211.

34. Thomson, W.T.; Fenger, M. Case histories of current signature analysis to detect faults in induction motor drives. In Proceedings of the IEEE International Electric Machines and Drives Conference (IEMDC'03), Madison, WI, USA, 1-4 June 2003, Volume 3; pp. 1459-1465.

35. Culbert, I.M.; Rhodes, W. Using current signature analysis technology to reliably detect cage winding defects in squirrel cage induction motors. IEEE Trans. Ind. Appl. 2007, 43, 422-428. [CrossRef]

36. Hassan, O.E. Induction motor broken rotor bar fault detection techniques based on fault signature analysis-A review. IET Electr. Power Appl. 2018, 12, 895-907. [CrossRef]

37. Martin-Diaz, I.; Morinigo-Sotelo, D.; Duque-Perez, O.; de Romero-Troncoso, J.R. Advances in classifier evaluation: Novel insights for an electric data-driven motor diagnosis. IEEE Access 2016, 4, 7028-7038. [CrossRef]

38. Dias, C.G.; de Sousa, C. A Neuro-Fuzzy Approach for Locating Broken Rotor Bars in Induction Motors at Very Low Slip. J. Control Autom. Electr. Syst. 2018, 29, 489-499. [CrossRef]

39. Dias, C.G.; Pereira, F.H. Broken Rotor Bars Detection in Induction Motors Running at Very Low Slip Using a Hall Effect Sensor. IEEE Sens. J. 2018, 18, 4602-4613. [CrossRef]

40. Gangsar, P.; Tiwari, R. Comparative investigation of vibration and current monitoring for prediction of mechanical and electrical faults in induction motor based on multiclass-support vector machine algorithms. Mech. Syst. Signal Process. 2017, 94, $464-481$. [CrossRef] 
41. Lei, Y. Intelligent Fault Diagnosis and Remaining Useful Life Prediction of Rotating Machinery; Butterworth-Heinemann: Oxford, UK, 2017.

42. Skowron, M.; Wolkiewicz, M.; Orlowska-Kowalska, T.; Kowalski, C.T. Application of Self-Organizing Neural Networks to Electrical Fault Classification in Induction Motors. Appl. Sci. 2019, 9, 616. [CrossRef]

43. Mirzaeva, G.; Saad, K.I. Advanced Diagnosis of Rotor Faults and Eccentricity in Induction Motors Based on Internal Flux Measurement. IEEE Trans. Ind. Appl. 2018, 54, 2981-2991. [CrossRef]

44. Dias, C.G.; Chabu, I.E. Spectral analysis using a Hall effect sensor for diagnosing broken bars in large induction motors. IEEE Trans. Instrum. Meas. 2014, 63, 2890-2902. [CrossRef]

45. Mirzaeva, G.; Saad, K.I.; Jahromi, M.G. Comprehensive Diagnostics of Induction Motor Faults Based on Measurement of Space and Time Dependencies of Air Gap Flux. IEEE Trans. Ind. Appl. 2017, 53, 2657-2666. [CrossRef]

46. Dias, C.G.; Chabu, I. A new method to detect broken rotor bars in large induction motors. In Proceedings of the 1st International Conference on Electrical Engineering, Vancouver, BC, Canada, 30-31 January 2019; pp. 27-31.

47. Chow, M. Methodologies of Using Neural Network and Fuzzy Logic Technologies for Motor Incipient Fault Detection; Word Scientific Publishing Co. Pte. Ltd.: Singapore, 1997.

48. Chandralekha, R.; Jayanthi, D. Diagnosis of Faults in Three Phase Induction Motor using Neuro Fuzzy Logic. Int. J. Appl. Eng. Res. 2016, 11, 5735-5740.

49. Laala, W.; Guedini, S.; Zouzou, S. Novel approach for diagnosis and detection of broken bar in induction motor at low slip using fuzzy logic. In Proceedings of the 8th IEEE Symposium on Diagnostics for Electrical Machines, Power Electronics Drives, Bologna, Italy, 5-8 September 2011; pp. 511-516.

50. Amezquita-Sanchez, J.P.; Valtierra-Rodriguez, M.; Perez-Ramirez, C.A.; Camarena-Martinez, D.; Garcia-Perez, A.; Romero-Troncoso, R.J. Fractal dimension and fuzzy logic systems for broken rotor bar detection in induction motors at start-up and steady-state regimes. Meas. Sci. Technol. 2017, 28, 075001. [CrossRef]

51. Fernandez-Temprano, M.; Gardel-Sotomayor, P.E.; Duque-Perez, O.; Morinigo-Sotelo, D. Broken bar condition monitoring of an induction motor under different supplies using a linear discriminant analysis. In Proceedings of the 2013 9th IEEE International Symposium on Diagnostics for Electric Machines, Power Electronics and Drives (SDEMPED), Valencia, Spain, 27-30 August 2013; pp. 162-168.

52. Theodoridis, S. Machine Learning: A Bayesian and Optimization Perspective; Academic Press: Cambridge, MA, USA, 2015.

53. Martin-Diaz, I.; Morinigo-Sotelo, D.; Duque-Perez, O.; Romero-Troncoso, R.J. An Experimental Comparative Evaluation of Machine Learning Techniques for Motor Fault Diagnosis Under Various Operating Conditions. IEEE Trans. Ind. Appl. 2018, 54, 2215-2224. [CrossRef] 